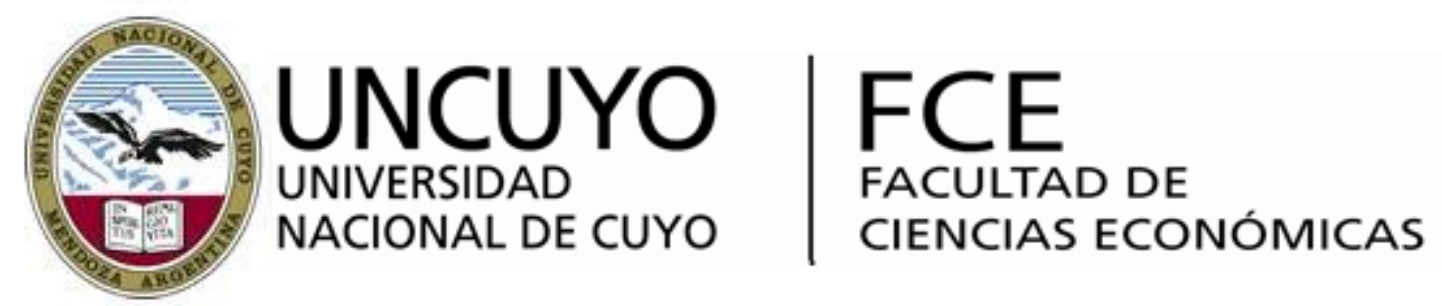

Carrera: Licenciatura en Administración

\title{
Reclutamiento y selección 2.0
}

Análisis e interpetación de especialistas en el tema

Trabajo de Investigación

\author{
POR \\ Ramirez, Maria Florencia \\ Reg:26341 \\ ramirez.florencia@hotmail.com
}

Profesor Tutor

Ramiro Noussan Lettry

Mendoza - 2019 


\section{RESUMEN}

El presente trabajo tiene como finalidad el análisis de las herramientas actuales que se utilizan en la búsqueda de personal, realizando un repaso del desarrollo histórico del área. El mismo, pretende brindar un aporte a la Gestión de Personal, acerca de las nuevas metodologías implementadas en las tareas de reclutamiento y selección.

En un principio, se presentará una evolución histórica del área de personal, desde la Administración científica hasta la gestión de competencia, haciendo hincapié en aquellas en las principales teorías.

A continuación, se realizará un repaso por los conceptos básicos de reclutamiento y selección de personal dada por los autores más clásicos, así como también, las técnicas más tradicionales para incorporar personal.

Luego, se presentarán las técnicas de gestión de personal que hoy son tendencia y la adaptación de las tareas de reclutamiento y selección con las herramientas informáticas actuales.

Por último, se mostrará la aplicación de las técnicas precedentes, tanto a nivel internacional como a nivel provincial, gracias a informes globales y a entrevistas realizadas a especialistas en el tema de Mendoza.

Palabras clave: reclutamiento, selección, gestión de personal, nuevas tendencias, web 2.0, redes sociales, Mendoza 
INTRODUCCIÓN

FORMULACIÓN DEL PROBLEMA

OBJETIVOS: $\quad 6$

Objetivos generales $\quad 6$

Objetivos específicos 6

HIPÓTESIS DE TRABAJO $\quad 6$

ESTRATEGIA METODOLÓGICA $\quad 6$

ESTRUCTURA DE LA INVESTIGACIÓN

CAPÍTULO I : DESARROLLO HISTÓRICO DE LA FUNCIÓN DE PERSONAL 8

1) PRINCIPALES MODELOS DE GESTIÓN DE PERSONAS 8

2) GESTIÓN POR COMPETENCIAS

2.1 IMPORTANCIA $\quad 12$

2.2 CONCEPTO 12

2.3 ¿POR QUÉ ES RELEVANTE EN LA GESTIÓN DE PERSONAL? 14

CAPÍTULO II: LOS RECURSOS HUMANOS COMO ÁREA ORGANIZACIONAL. 19

1) DEFINICIÓN

2) SUBSISTEMAS O ÁREAS DE PERSONAL

3) PRINCIPALES FUNCIONES DEL ÁREA DE RECURSOS HUMANOS O CAPITAL HUMANO 20

4) LAS BASES DE RECLUTAMIENTO Y SELECCIÓN.

4.1 RECLUTAMIENTO: DEFINICIÓN Y CARACTERÍSTICAS.

4.1.1 Fases del reclutamiento de personal: $\quad 21$

4.1.2 El proceso de reclutamiento $\quad 22$

4.1.3 Medios de reclutamiento 22

4.2 SELECCIÓN DE PERSONAL: DEFINICIÓN Y CARACTERÍSTICAS 24

4.2.1 Bases para la selección de personas 26

4.2.2 Elección de las técnicas de selección. 26

CAPÍTULO III: NUEVAS TENDENCIAS EN LA GESTIÓN DE PERSONAS 28

1) FORMAS NOVEDOSAS DE GESTIONAR EL PERSONAL 28

1.1 Gestión del conocimiento: 28

1.1.1 Hacia un concepto de conocimiento: $\quad 30$

1.1.2 Características del conocimiento 31 
$\begin{array}{ll}\text { 1.1.3 Tipos de conocimiento } & 31\end{array}$

$\begin{array}{ll}\text { 1.1.4 Modelos de la Gestión del conocimiento } & 31\end{array}$

1.1.5 Relevancia del conocimiento en la gestión de personas 33

1.2 Dirección por valores $\quad 34$

1.2.1 Definición de valor $\quad 34$

1.2.2 Definición de dirección por valores $\quad 34$

$\begin{array}{ll}1.2 .3 \text { Implementación } & 34\end{array}$

1.2.4 Cuál es la importancia. $\quad 35$

1.2.5 Por qué aún falla este modelo de gestión 35

1.3 Gestión del bienestar $\quad 36$

1.3.1 Un modelo de bienestar organizacional: corazones at work 36

$\begin{array}{lll}\text { 1.3.2 ¿Por qué es importante? } & 37\end{array}$

CAPÍTULO IV: LAS NUEVAS TÉCNICAS DE RECLUTAMIENTO Y SELECCIÓN 39

1) ATRACCIÓN DE PERSONAS 39

1.1 ¿Qué es la marca empleadora? $\quad 40$

1.2 ¿Por qué utilizarla? $\quad 40$

$\begin{array}{lr}\text { 2) RECLUTAMIENTO } 2.0 & 40\end{array}$

3) LOS SOFTWARE DE RECURSOS HUMANOS 46

4) SELECCIÓN $\quad 47$

$\begin{array}{lll}4.1 & \text { Nuevos métodos para la selección } 2.0 & 47\end{array}$

CAPÍTULO V: INFORME DEL TRABAJO DE CAMPO

1) Informes internacionales $\quad 50$

2) Entrevistas personales $\quad 50$

$\begin{array}{lr}\text { CONCLUSIONES } & 58\end{array}$

BIBLIOGRAFÍA

$\begin{array}{lr}\text { ANEXOS } & 62\end{array}$ 


\section{INTRODUCCIÓN}

Las organizaciones siempre han comprendido a las personas que trabajan en ellas como parte fundamental para el logro de sus objetivos. Sin su presencia, la organización pierde sentido, y de forma contraria también: la importancia del trabajo en una persona no sólo radica en la faz económica para poder lograr un sustento personal o capacidad de consumo, sino que también lo hace parte de su objetivo de vida.

A medida que la fuerza de trabajo fue evolucionando, también lo hicieron las teorías que buscaban la eficiencia en la tarea: así, se pasó del estudio de tiempos y movimientos de Federick Taylor y la máquina de vapor, hasta las teorías que buscan administrar el conocimiento, en una época donde el mismo es el factor de ventaja competitiva.

El presente trabajo de investigación está enfocado en explorar la evolución que ha tenido la teoría de la administración con relación al recurso humano y cómo ésta afecta a las tareas de reclutamiento y selección, las cuales se han visto modificadas por las nuevas tecnologías de comunicación: la web 2.0.

Guárdia (2007: pág 36) define a la web 2.0 como

"Todas aquellas utilidades y servicios de Internet que se sustentan en una base de datos, la cual puede ser modificada por los usuarios del servicio, ya sea en su contenido (añadiendo, cambiando o borrando información o asociando a metadatos a la información existente), bien en la forma de presentarlos o en contenido y forma simultáneamente"

En un principio se presentarán las teorías de administración más importantes y las definiciones y herramientas básicas para las tareas de reclutamiento y selección de personal.

A continuación, se expondrán las nuevas teorías sobre administración del personal y los cambios en la función de personal a partir de las mismas. Así mismo se expondrán las herramientas que la web 2.0 brinda para el reclutamiento y selección.

Por último, se investigará tanto a nivel internacional como provincial, el impacto y uso que tienen las teorías y herramientas nuevas, en la búsqueda de la eficiencia en esta tarea. 


\section{FORMULACIÓN DEL PROBLEMA}

El problema detectado es que dados los cambios tanto generacionales como en el entorno, las organizaciones han tenido que adaptarse a los mismos: primero, atendiendo a las nuevas demandas de los clientes y dejando al Departamento de Personal con procesos anticuados en sus prácticas de reclutamiento, selección y desarrollo del personal, pudiendo generar una situación de ineficiencia en los procesos de incorporación de personal.

\section{OBJETIVOS:}

\section{Objetivos generales}

Los objetivos generales a los que pretende llegar el siguiente trabajo son los siguientes:

1. Detallar la evolución de la Gestión en Personal a través del tiempo. Diversas maneras de reclutar y seleccionar personas.

2. Investigar el uso de la tecnología que llevan a cabo los encargados del área.

3. Brindar un aporte al área de Gestión en Personal sobre las últimas herramientas que están siendo implementadas.

\section{Objetivos específicos}

1) Revisar cuáles son las tareas básicas en el reclutamiento y selección.

2) Explorar las nuevas tendencias en la gestión de personas.

\section{HIPÓTESIS DE TRABAJO}

La aplicación de los métodos 2.0 para la búsqueda del personal, permite un mayor ahorro en el tiempo y una mayor eficiencia en dicha tarea.

\section{ESTRATEGIA METODOLÓGICA}

Para esta investigación, se utilizará como sustento teórico, los conceptos de reclutamiento y selección de personal analizados a lo largo de la carrera y en la bibliografía especializada sobre el tema, teniendo en cuenta distintos aspectos y metodologías asociadas a estos procesos. Se tendrá en cuenta como referencia a empresas de la Provincia de Mendoza que posean un departamento de personal o al menos, realicen reclutamiento y selección de manera periódica y que hayan cambiado sus métodos relacionados, al menos, en un corto tiempo, de manera que se pueda medir su impacto. 
Se realizarán entrevistas a referentes del sector por medio de los cuales pueda conocerse acerca de la implementación de los métodos 2.0 en gestión de personal, en empresas de Mendoza.

\section{ESTRUCTURA DE LA INVESTIGACIÓN}

En el primer capítulo se hará mención de las principales teorías en la administración a lo largo de la historia y su vínculo con los recursos humanos: desde el modelo tradicional hasta la gestión por competencias.

En el segundo capítulo se desarrollará los principales conceptos de la administración del personal, haciendo énfasis en las tareas de reclutamiento y selección, las herramientas clásicas que se han utilizado para lograr la incorporación de personal a las empresas.

En el tercer capítulo, se abordarán las nuevas técnicas en la gestión de personas, por qué se utilizan y cuáles son sus principales características.

En el cuarto capítulo, se explicarán cuáles son las nuevas tendencias en reclutamiento y selección 2.0, analizando cada una de las herramientas disponibles o en desarrollo y sus características más importantes.

En el quinto capítulo, se podrá observar la experiencia actual que hay a nivel internacional y provincial, su punto de vista sobre las formas de gestión de personas y su experiencia en el uso de las herramientas 2.0, a través de informes y entrevistas realizadas a reclutadores y expertos en el tema.

Para finalizar, se cerrará el trabajo con las conclusiones y la bibliografía consultada. 


\section{Capítulo I: DESARROLLO HISTÓRICO DE LA FUNCIÓN DE PERSONAL}

Antes de situar el panorama actual y las herramientas utilizadas en la selección y reclutamiento de personal, es necesario enmarcar el avance que ha tenido la Gestión de Personal a lo largo de los años.

Para ello es pertinente mencionar que a medida que el tiempo ha pasado y diversos acontecimientos han cambiado la manera de hacer negocios y mantener una empresa, también ha avanzado la forma de gestionar al personal. Sobre todo, remarcar que la función de Personal es la expresión de los cambios que se produjeron en la industria.

\section{1) PRINCIPALES MODELOS DE GESTIÓN DE PERSONAS}

En virtud de esto, Abarzúa, Contreras y Robles (2011) hacen mención a cuatro modelos de gestión que explican distintas formas de llevar la gestión de personas, a lo largo del tiempo.

1. Modelo tradicional:

El acontecimiento industrial que marca esta etapa es la Segunda Revolución Industrial (Siglos VII y VIII). Este acontecimiento está marcado, según Cabuya Montaño (1999) por estos cambios:

- Aparición de las industrias y la producción masiva (empresas de electricidad, textil, entre otras): esto trae aparejado que exista mayor distancia entre el trabajador y el empleador, empieza a ser necesaria la coordinación de tareas y las condiciones de trabajo en esa época eran precarias (trabajo a mujeres y niños, excesivas jornadas laborales, etc)

- Aparición de las maquinarias: la existencia de la máquina provocó el éxodo de las personas que trabajaban en la agricultura, a los principales centros urbanos.

- Empieza la exportación a los distintos mercados internacionales, con la aparición del tren y barcos propulsados a vapor.

- Surge el trabajo asalariado.

A raíz de estas características, comienzan a aparecer varios estudios sobre cómo organizar el trabajo ya que, lo principal que tenían en mente los dueños de empresas, era cómo mejorar la productividad de las plantas. Por ello, surgen los estudios de Frederick Taylor, uno de los principales referentes de la "administración científica", la cual se basa en: 
- La estandarización y descripción de la tarea, como resultado de buscar una eficiencia en la ejecución de tareas. Por estandarización, entendemos como establecer un patrón o modelo de referencia para poder controlar una tarea o producción. Por ejemplo, la cantidad de producto que tiene que producir una persona en cierto tiempo, es un buen estándar. La descripción de la tarea son todas las acciones que debe realizar una persona en un determinado puesto de trabajo. Las acciones de los operarios "mientras mas simples y repetitivas fueran (..) tanto mayor sería la eficiencia de las mismas" Chiavenatto (2007)

- La aparición de los mandos medios en las estructuras organizacionales. Surgen los supervisores, gerentes, jefes y empieza a tenerse en cuenta la jerarquía en las organizaciones.

- El único incentivo que existía para el empleado, era el económico. A mayor salario, mayor producción.

- La necesidad de selección y entrenamiento del personal: Se busca al personal adecuado para ocupar un puesto determinado y se lo capacita de acuerdo a lo que la empresa busca.

En el área de Personal, los individuos realizan las diversas tareas tanto de producción como de administración, sin que exista un órgano encargado de las mismas (dotación de personal, capacitación, remuneraciones, reclutamiento y selección, análisis de puestos). A medida que se ve una mejora de en las toma de decisiones de la organización, el área administrativa toma más relevancia.

2. Modelo de las relaciones humanas:

Surge como respuesta de la administración científica. En 1926, en la Western Electric Company, en Chicago surge el experimento de Hawthorne, el cual marca el comienzo de esta escuela.

En el mismo, según (Hart, 2012) Elton Mayo y sus colaboradores, someten a grupos de operarios (de no más de 5 participantes) que realizaban tareas de montaje a diversos estudios para medir su productividad: primero, evaluaron las condiciones ambientales (iluminación, temperatura), luego periodos de descanso, entre otros.

En un comienzo, la manera de evaluar los resultados era por indicadores de productividad, como por ejemplo, la cantidad de productos terminados por hora. Al tomar ese parámetro de evaluación, no llegaban a ningún resultado concluyente, pues no eran variables correlativas: no importaba la iluminación o la cantidad de descanso, la productividad iba en aumento. Luego, comenzaron a 
solicitar el asesoramiento de psicólogos, antropólogos y sociólogos (inusual en esos tiempos) y mediante la utilización de entrevistas a los empleados involucrados, llegaron a la conclusión de que lo que hacía que aumentara la producción eran los factores sociales: las personas dejaban de ser parte de las maquinarias y empiezan a valorizarse las relaciones entre ellas; comienza el estudio de los grupos sociales, y se descubre que en cada parte de la organización no es igual en este punto. Surgen así conceptos como liderazgo, motivaciones intrínsecas y la importancia de la comunicación.

Estos experimentos siguieron hasta 1930 aproximadamente, cuando la Gran Depresión y su crisis provocó que fuera suspendido.

En este modelo surgen la Administración de Personal (con tareas como la descripción de puestos, reclutamiento y selección, capacitación y remuneraciones) y las Relaciones Laborales (regulación de la relación empleador - empleado).

3. Modelo de Recursos Humanos:

Ya en la década de los 70, los departamentos de personal cambian su nombre a Recursos Humanos, adquiriendo así, el mismo status que las áreas de Producción, Ventas y Finanzas. A pesar de ello, es considerada área de staff o de apoyo a las otras.

Comienzan los estudios sobre el comportamiento y desarrollo organizacional; según Gonzalez (1999), se define al comportamiento organizacional como

"una disciplina científica que analiza el comportamiento del individuo y grupos de cara a facilitar la dirección de ese comportamiento".

Empiezan a evaluarse variables y procesos individuales y grupales, como motivación, liderazgo; es decir, estudian el comportamiento organizacional, pero a nivel micro: surgen los modelos que, por ejemplo, explican el ciclo del estrés en el trabajo.

Las tareas relevantes de la función de personal son dotación, actualización y mejoramiento del personal y mantención, desarrollo y desvinculación del personal.

4. Modelo de Gerencia Estratégica de Recursos Humanos: 
Comenzando el año 1990, y gracias a al enfoque conductista las teorías de sistemas y contingencias, comienza un análisis del comportamiento organizacional más amplio, macro en comparación a anterior, que permite explicar qué era lo que le pasaba a la empresa o explicara su comportamiento ante los cambios (cambios legales, de fuerza laboral y, sobre todo, la globalización del mercado).

El principal cambio que ve Gonzalez (1999) en los recursos humanos puede resumirse en los siguientes aspectos:

1) Son percibidos como una ventaja competitiva: comienza el cambio de visión del recurso humano, cambiando su perspectiva de costo a disminuir, por un elemento que agrega valor a las organizaciones.

2) La dirección es proactiva, ya que es necesario que sea anticipadora de cambios, pasando de una acción pasiva ante los cambios en el contexto, a una acción proactiva.

3) La perspectiva estratégica: los recursos humanos acompañan, por medio de su actividad, a alcanzar los objetivos propuestos por la organización, y para ello, esas actividades deben ser planificadas, organizadas, dirigidas y controladas; se establecen más detalladamente, la competencia del área, donde también surgen distintas subunidades que se hacen cargo de las distintas tareas.

Si bien esta forma de organizar el trabajo tiene muchas ventajas, los autores Abarzúa, Contreras y Robles (2011) señalan que, ante la importancia creciente al análisis de procesos, la gestión de Recursos Humanos deba cambiar su enfoque funcional.

Aquí, según señalan los autores, se encuentra una contradicción: por un lado, abogamos por una gerencia de recursos humanos centralizada, con tareas que puedan ser distinguidas de las otras áreas, y por el otro, el enfoque de procesos y de pensar más allá de lo meramente competente a la función del área y un trabajo más en conjunto, entonces, ¿cómo solucionarlo? Simplemente, con la distinción de los factores estratégicos de los operativos. Es decir, que si desde el área pueden centralizarse los temas más importantes (como sería un plan del área, políticas para tomar personal, procedimientos para solicitar capacitaciones) de los que pueden tomarse de forma autónoma, como los procesos de inducción de personal o el análisis y diseño de puestos

Es decir, que si desde el área pueden centralizarse los temas más importantes, tales como podría ser realización de un plan para el área, o bien las políticas para el reclutamiento y selección de personal o los procedimientos involucrados para la realización de capacitaciones, de aquellos que pueden 
ejecutarse de modo autónomo, como puede ser la inducción del personal o el análisis y diseño de puestos.

\section{2) GESTIÓN POR COMPETENCIAS}

\subsection{IMPORTANCIA}

La gestión por competencias surge de la adaptación de la teoría de rasgos que antes existía a la hora de tomar personal. Cuando se expresa "rasgos" se hace referencia a las características de los rasgos psicométricos que tiene que tener una persona para poder cumplir las exigencias de un cargo. La principal desventaja que presenta esta teoría es que presenta a los rasgos como una característica permanente en una persona, imposible que se puedan cambiar. La otra desventaja, es que los test que lo predicen, no terminan proyectando el desempeño de una persona en un determinado cargo.

Muchos autores utilizan los términos puesto y cargo como si fueran sinónimos y es necesario diferenciarlos.

Hernandez y Lezama, (2008) definen al puesto como el espacio físico donde las personas realizan sus tareas dentro de una determinada empresa: una oficina, un piso; en cambio, el cargo está relacionado al lugar jerárquico que ocupa una persona en una estructura organizacional: son sus responsabilidades y funciones. Los autores antes mencionados finalizan este problema diciendo que "un cargo lo ocupa solo una persona, mientras que varias personas pueden compartir un puesto de trabajo"

La gestión por competencias cambia el punto de vista de análisis de la gestión de personal: lo considera un elemento fundamental en el desarrollo de una organización, dejando de lado la visión de "recursos humanos"; Según Moreno Dominguez, Diaz Pelayo, \& Sanchez Vargas, (2004) desarrolla a las personas para que puedan aportar lo mejor de sí mismos y que dicho aporte contribuya al logro de los objetivos de la organización.

\subsection{CONCEPTO}

Según Pereda Marín, Berrocal y Quero (2002) es posible definir a la competencia como:

"conjunto de comportamientos observables que llevan a desempeñar eficaz y eficientemente un trabajo determinado en una organización concreta". 
Para Moreno et al (2004), el enfoque de competencias se centra primero en la eficiencia en el desempeño de una tarea y a partir de allí, define los comportamientos que llevan a ese resultado y entonces especificarlos como competencia. También es preciso mencionar que la competencia no es una definición generalista, sino que está vinculada a un contexto laboral concreto.

Los elementos necesarios para definir una competencia laboral son:

1) Saber: para Moreno et al (2004) son el conjunto de conocimientos que permiten a una persona llevar a cabo los comportamientos que conforman una competencia. Por ejemplo, un mecánico de autos tiene que tener conocimientos acerca de las distintas partes de un auto, los componentes, su interacción, etc.

García-Saíz( 2011) aclara que este tipo de información o conocimiento no es solo un conocimiento explícito, sino también declarativo. Este recurso adquiere otro nivel de importancia cuando se tiene en cuenta que el contexto a aplicar es el correcto para el tipo de conocimiento

2) Saber hacer: según Moreno et al (2004) es la capacidad o habilidad de poner ese conocimiento en práctica. (Bandura, 1987; Ca-ballo, 1993; Costa y López, 2006; Gavino, 2008; Sternberg, 2005; Zaccagnini, 2004) en García-Saíz (2011, p. 491) presenta la siguiente clasificación:

- Habilidades cognitivas: es la capacidad de aprendizaje, la elaboración de escenarios, análisis de situaciones, entre otros aspectos

- Emocionales: es el conocimiento y regulación de nuestras propias emociones y cómo podemos utilizarlas para el logro de los objetivos

- Sociales: son las que se utilizan para establecer relaciones interpersonales

- Técnicas: no está dirigida a una persona, sino a recursos; por ejemplo, el manejo de herramientas informáticas.

3) Saber estar: es la actitud y los intereses de una persona, y su comportamiento bajo las normas de la organización. Están relacionadas con las creencias, valores y actitudes: "son nuestras tendencias o preferencias personales y su relación con el contexto en el que se manifiestan" García-Saíz( 2011)

4) Querer hacer: Para Moreno et al (2004) es el interés y la motivación que posee una persona al realizar una tarea. (García-Saíz, 2011, p. 491) incluye en la clasificación de motivaciones la de Latham y Pinder (2005) sobre cómo las variables emocionales y estados de ánimo afectan el logro de los objetivos de la organización 
"La justicia organizacional plantea que las personas hacen un balance entre lo que realizan en el trabajo, lo que reciben de la organización y lo comparan con lo que obtienen los demás"

Si hay una percepción de injusticia, esto genera reacciones emocionales (como tristezas, enojos) y conductuales (sabotaje, rotación, mal desempeño en la función, etc)

5) Poder hacer: que cuente con los recursos que se necesitan para poder realizar la tarea.

\section{3 ¿POR QUÉ ES RELEVANTE EN LA GESTIÓN DE PERSONAL?}

Según Moreno et. Al (2004) es relevante la gestión por competencias en el área de personal en las siguientes áreas:

- Dentro del proceso de reclutamiento y selección de personal: para poder seleccionar por competencias, es necesario que previamente se realice el análisis y diseño de puestos teniéndolas en cuenta. Para ello debe cumplirse los siguientes parámetros:

1) Debe explicársela detalladamente

2) Cada competencia tiene distintos niveles que pueden analizarse bajo criterios observables.

3) Las competencias pueden desarrollarse, es decir, se puede aumentar o disminuir.

4) Diferenciar las competencias genéricas de las técnicas.

5) Deben identificarse las competencias en orden de prioridades, desde las más críticas hasta aquellas que se pueden prescindir. Para ello, Lévy-Leboyer (2000) señala las siguientes herramientas:

a) la observación directa: junto con la ayuda de un anterior análisis de cargo, se realiza un relevamiento de los comportamientos más importantes

b) auto describir la tarea: se le pide a la persona que ejecuta el cargo, que ella misma tome nota de sus comportamientos. De esta forma, pueden relevarse actividades de tipo intelectuales (como la toma de una decisión) que solo con la observación directa no alcanzaría.

Esto permite que, en el caso que se tomen varias auto-descripciones del mismo cargo, se llega a conceptos más amplios debido a los distintos enfoques que cada uno aporta. 
c) entrevistas: mediante preguntas ya planificadas o no, la entrevista tiene por objetivo lograr un acercamiento sobre el trabajo que realiza una determinada persona.

Si bien estas herramientas son muy subjetivas, sirven para un primer relevamiento y acercamiento de la tarea.

Otros métodos para poder relevar competencias son:

a) análisis de incidentes críticos:

Para Perez Montejo (2009) este estudio implica tomar nota de los hechos más destacados que tiene una persona en la elaboración de una tarea o desempeño de su puesto, estos hechos pueden ser tanto positivos como negativos, dejando anotado qué hizo, qué no y qué debería haber hecho.

Luego, estos hechos se presentan a la persona que los realizó mediante una entrevista y se discute sobre los mismos. Es importante señalar que los incidentes críticos no se analizan de manera aislada, sino que se detalla el contexto en el cual suceden.

b) Panel de expertos:

Consiste en generar un grupo de personas especializadas en distintas áreas que colaboren en la identificación de las competencias según Gallego (2000), estas pueden ser:

área administrativa: que verifique el proceso y dé una perspectiva general de la organización

gestión humana: es quien lidera el proceso y quien guía y acompaña a las demás áreas

área específica de estudio: es el experto en el área y conoce los procesos que hay en la misma y sabe qué es correcto y que no, en el desempeño

Cabe aclarar que las herramientas mencionadas pueden utilizarse para la selección de personal, lo que no significaría una desestimación de las herramientas consideradas en un enfoque "tradicional", sino una adecuación de las mismas, pero con el criterio de competencias.

- Dentro del proceso de formación y desarrollo: 
Son las actividades necesarias para llegar al nivel de competencia deseado. Para ello, existen las siguientes herramientas:

a) El coaching:

El método para el desarrollo de las competencias más utilizado actualmente es el coaching: según Martínez González (2001) se lo puede definir como un proceso por el cual se logra un mejoramiento en las habilidades y competencias tanto de una persona, como de un equipo de trabajo.

El coach, asume varios roles que implica señalar las áreas a mejorar o le da las herramientas a la persona para que pueda identificarlas por sí sola, y el cliente, tiene que tener en cuenta que el coach es sólo una guía y que de él depende cambiar ciertas y determinados patrones de conducta y elevar la productividad.

La clasificación de coaching para Escobar Valencia (2005) incluye los siguientes aspectos:

$\checkmark \quad$ Individual: necesidad de desarrollo de una persona.

$\checkmark$ Grupal: diseño de un programa para mejorar el desempeño de un grupo, utilizando actividades grupales

$\checkmark$ Mixto: intenta llegar a la mejora del desempeño de un grupo mediante actividades grupales e individuales.

b) El Mentoring:

Para Escobar Valencia, (2005, pág 48) el mentoring puede definirse como:

"un proceso de mejora guiado, flexible y con apoyo continuo que logra el desarrollo del participante, preparándolo en la comprensión de temas personales, organizativos y/o políticos que pueden afectar su desempeño actual como su futuro"

Gasalla Dapena (2003) da una diferencia entre coach y mentoring, basándose que este último suele ser una persona con muchos años en la organización y transmite los conocimientos tácitos; mientras que el coach suele ser alguien externo y llama más a la autorreflexión.

c) El autodesarrollo 
Otra manera de desarrollar las competencias es el auto desarrollo; es decir que el proceso de crecimiento en competencias sea realizado individualmente, sin la participación de un externo; para ello es necesario que las personas cuenten con un alto nivel de disciplina y autoconfianza.

En cuanto al Plan de Carrera, sucede lo mismo que con el análisis y diseño de puestos: tiene que estar definido a través de competencias y si existe el interés en ascender el individuo podrá desarrollar las competencias que son necesarias para ese puesto. Para ello será necesario comprender qué aspiración tiene cada persona para poder trazar un plan de carrera adecuado.

\section{- Dentro del proceso de recompensas y sanciones:}

Según Capuano (2004) en la evaluación de desempeño por competencias, es un proceso en el cual se deduce la performance de un empleado y se tiene en cuenta que no todas las personas "Son competentes para todas las tareas y no se está interesada en todas las tareas por igual"

Un método novedoso para el proceso de evaluación de desempeño es "Evaluación 360" en el cual se involucra a todos los sectores que constituyen el entorno del desempeño de una persona.

Las ventajas que presenta el modelo según Green (2002) citado por Pereira M, P., Lily, \& P.Monica, (2008) son:

+ mejora la calidad de las medidas de desempeño, ya que quienes proveen información, son las personas con las que el empleado interactúa regularmente, haciéndolas válidas

+ la información es más creíble y confiable al ser varios evaluadores. En la evaluación tradicional, el único que podía hacerla, era el supervisor directo

+ permite identificar las fortalezas de los sujetos y las distancias que se encuentra entre lo esperado o deseado vs lo percibido

La evaluación 360 propone, según los mismos autores, incluye las siguientes etapas:

- $90^{\circ}$ evaluación de los colegas: las personas que están en el mismo nivel jerárquico conocen a la persona de la evaluación. Pueden estar en otros departamentos e interactuar informalmente

- $180^{\circ}$ revisión ascendente: la o las personas a las que se reporta o rinde cuentas 
- $270^{\circ}$ autoevaluación: el sujeto tiene la posibilidad de evaluar las competencias que posee y su desempeño

- $360^{\circ}$ revisión descendente: son los que están bajo su línea de mando. Es rica la información que pueden aportar ya que pasan mucho tiempo con el sujeto evaluado.

A lo largo de este capítulo se ha abordado el desarrollo histórico de la gestión de personal de modo tal de brindar el marco general para abordar en los capítulos siguientes aspectos específicos del tema de investigación. 


\section{Capítulo II: LOS RECURSOS HUMANOS COMO ÁREA ORGANIZACIONAL.}

En este capítulo se abordarán las clásicas definiciones que brinda la literatura sobre los Recursos Humanos, las tareas que implica la función y principalmente, el concepto de reclutamiento y selección, haciendo mención de las herramientas más utilizadas.

\section{1) DEFINICIÓN}

La Administración de Recursos Humanos es, según Chiavenato (2001):

"planear, organizar, desarrollar, coordinar y controlar, técnicas capaces de promover el desempeño eficiente del personal, al mismo tiempo que la organización representa el medio que permite a las personas que colaboran en ella alcanzar los objetivos individuales, relacionados directa o indirectamente, con el trabajo".

Esta área, tiene tanto responsabilidad de línea como de staff; Alles (2013), da la siguiente clasificación:

* De línea: porque el responsable de recursos humanos está autorizado para supervisar el trabajo de sus subordinados y es responsable del cumplimiento de los objetivos de la organización

* De staff: el responsable de RR.HH también asesora y asiste a los demás gerentes de línea.

2) SUBSISTEMAS O ÁREAS DE PERSONAL

Para Chiavenato (2001) los principales objetivos de la Administración de los Recursos humanos, pueden dividirse en sub áreas con distintas actividades:

$\checkmark$ Subsistema de Provisión de Recursos Humanos: implica actividades como la investigación de mercado, reclutamiento y selección de personal. En ésta área, es en la que se centrará la investigación.

$\checkmark$ Subsistema de Aplicación de Recursos Humanos: incluyen los primeros pasos de la integración de los nuevos miembros en la organización, el diseño del cargo que debe desempeñarse y la evaluación de desempeño en el cargo

$\checkmark$ Subsistema de Mantenimiento de Recursos Humanos: abarca los planes de compensación monetaria, beneficios sociales e higiene y seguridad en el trabajo. 
$\checkmark$ Subsistema de Desarrollo de Recursos Humanos: Son las actividades de entrenamiento, desarrollo de personal y desarrollo organizacional.

$\checkmark$ Subsistema de Control de Recursos Humanos: son las bases de datos y sistema de información y auditoria de los recursos humanos.

A continuación, en la siguiente figura pueden apreciarse los objetivos de la administración de recursos humanos en términos de "subsistemas".

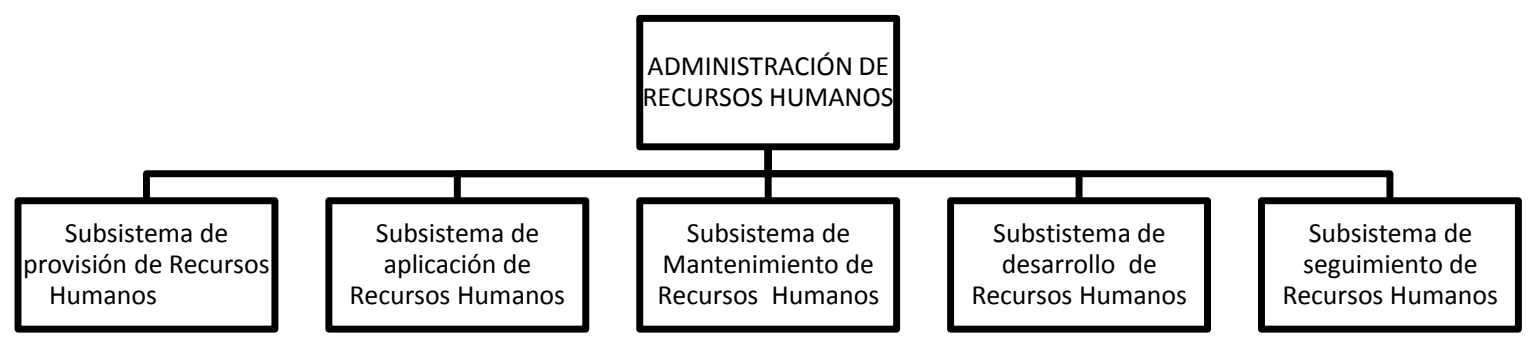

Fuente: Idalberto Chiavenato (2001), Administración de los Recursos Humanos

\section{3) PRINCIPALES FUNCIONES DEL ÁREA DE RECURSOS HUMANOS O CAPITAL HUMANO}

Si bien las funciones del área son muy parecidas, (Alles, 2013)hace una distinción entre aquellas que denomina "Área de Capital Humano" y "Oficina de Personal".

La primera, son aquellas funciones que no son impuesta por una ley, sino que devienen de las buenas prácticas. Y las segundas, son aquellas cuya función está prevista por las leyes de cada país.

Área de Capital Humano:

Desarrollo de personas: Formación de planes de carrera, planes de sucesión y desarrollo de competencias.

Empleos: Atracción, selección, incorporación e inducción de personas.

Compensaciones: Revisiones de salarios, políticas de beneficios, encuestas salariales para comparar con el mercado.

Oficina de Personal: 
Relaciones industriales: cuidado de la relación con los gremios u otras organizaciones sindicales.

Administración: aspectos administrativos en general; liquidación de haberes, control de ausentismo; etc.

\section{4) LAS BASES DE RECLUTAMIENTO Y SELECCIÓN.}

\subsection{RECLUTAMIENTO: DEFINICIÓN Y CARACTERÍSTICAS.}

Chiavenato (2001)define al reclutamiento de personal como

"conjunto de técnicas y procedimientos orientados a atraer candidatos potencialmente calificados y capaces de ocupar cargos dentro de la organización. El reclutamiento, llevado a cabo tomando como base de datos sobre necesidades presentes y futuras de recursos humanos de la organización, consiste en realizar actividades relacionadas con la investigación e intervención en las fuentes capaces de proveer a la organización el número suficiente de personas para conseguir los objetivos."

\subsubsection{Fases del reclutamiento de personal:}

Según Chiavenato (2001), el reclutamiento de personal pasa por las siguientes fases

a) Investigación interna sobre las necesidades: consiste en verificar las necesidades de la organización respecto a sus necesidades de recursos humanos a corto, mediano y largo plazo, para saber qué requiere de inmediato y cuáles son sus planes futuros de crecimiento y desarrollo que significarán nuevos aportes a los recursos humanos. Es decir, el objeto de estudio de esta etapa es ver qué es lo que está requiriendo la organización en cuanto a los perfiles que está buscando.

b) Investigación externa del mercado: es una investigación de mercado de recursos humanos orientada a segmentarlo y diferenciarlo para facilitar su análisis y consiguiente estudio

c) Definición de las técnicas de reclutamiento a implementar: la elección de las técnicas de reclutamiento dependerá del tipo de cargo que se está buscando. Es por ello, que es necesario realizar el análisis de cargos, esto es 
"la especificación del contenido, de los métodos de trabajo y de las relaciones con los demás cargos para cumplir requisitos tecnológicos, empresariales, sociales y personales del ocupante al cargo".

En cuanto al tipo de técnica a utilizar, se abordará en el capítulo siguiente.

\subsubsection{El proceso de reclutamiento}

Es importante señalar que el comienzo del proceso de reclutamiento depende de la decisión de la línea. Dado que el reclutamiento es una función de staff, sus actos dependen de una decisión de línea, que se oficializa mediante una especie de orden de servicio, generalmente denominada solicitud de empleado o solicitud de personal. Para Chiavenato (2001), cuando el órgano de reclutamiento la recibe, verifica en los archivos, si está disponible algún candidato adecuado; sino, debe reclutarlo a través de las técnicas de reclutamiento más indicadas para el caso.

\subsubsection{Medios de reclutamiento}

El mercado de recursos humanos presenta diversas fuentes que la empresa debe identificar y localizar, con el propósito de atraer candidatos que suplan sus necesidades, a través de múltiples técnicas de reclutamiento.

El reclutamiento puede ser interno o externo, tal como se expresa a continuación:

\section{Reclutamiento Interno}

El reclutamiento interno es cuando, al presentarse determinada vacante, la empresa intenta llenarla mediante la reubicación de sus empleados. Es utilizado en las organizaciones cuando la economía crece y encontrar los perfiles buscados resulta de una tarea difícil.

La reubicación de los empleados, según Giacomelli Treviño (2009), puede ser:

a) Movimiento vertical: un ascenso, por ejemplo.

b) Movimiento horizontal: transferidos; ocupar el mismo lugar jerárquico pero en otro departamento.

c) Movimiento diagonal: transferidos con promoción. Ubicarse en otro departamento con distinto lugar jerárquico. 


\section{Herramientas para el reclutamiento interno}

Dessler (2009) menciona como fuentes para realizar el reclutamiento interno los registros de personal y bancos de datos de habilidades, donde se obtiene información de las competencias de las personas que trabajan actualmente en la organización y se cruza con la descripción de puesto vacante.

También, es necesaria la comunicación de la vacante mediante un anuncio interno de puestos, que es la notificación a los empleados, mediante un tablero de noticias o por correo electrónico, junto con la descripción de la tarea, remuneración, departamento y supervisor que lo requiera

\section{Ventajas y desventajas del reclutamiento interno.}

Dessler (2009) señala que ésta forma de reclutar personal se hace ya conociendo las fortalezas y debilidades de cada uno de los candidatos, producto del tiempo que llevan en la empresa.

También, es un medio para fidelizar al empleado con la empresa, y éste puede sentir más lealtad y compromiso con la misma. Es importante destacar que el proceso de inducción es menor y que, probablemente, necesite menos capacitación que los empleados externos, lo que reduciría el tiempo de adaptación al puesto.

En cuanto a las desventajas, podría señalarse que los empleados que se postulen a la vacante y no la obtuvieron, pueden sentirse desanimados, para esto es fundamental que se comuniquen las razones del rechazo y las medidas para ser aceptados en el futuro. Puede suceder, también, que se pida entrevistar a todos los candidatos internos, cuando ya el gerente sabe a quién quiere contratar. Los intereses personales son otra desventaja potencial. Si todos los gerentes provinieran de ascensos, mostrarían la tendencia a mantener el estatus quo cuando se necesita una nueva dirección.

\section{Reclutamiento externo:}

Este tipo de reclutamiento sucede cuando examina candidatos, reales o potenciales, disponibles o empleados, en otras empresas, y su consecuencia es una entrada de recursos humanos.

Según Equipo Vértice (2007) Las fuentes de reclutamiento externo pueden resumirse en las siguientes

- Base de datos de solicitudes: son los candidatos presentados de manera espontánea, o aquellos que han quedado de búsquedas anteriores. Para esto, es necesario tener un buen sistema de base de datos y que el mismo, se encuentre actualizado. 
- Empleados como agentes de reclutamiento: según se acude a la red de familiares, amigos y demás personas conocidas, para buscar nuevos empleados. Es una forma de menor costo de obtener personal, y que refuerza el vínculo del empleado con la organización.

- Agencias de reclutamiento: son organismos que recogen información de personas que están en búsqueda laboral y presentan sus datos a las empresas. Este intercambio puede ser gratuito o remunerado. A su vez, estas agencias pueden estas dirigidas a trabajo temporal o no.

- Centros de formación (universidades, escuelas técnicas, etc): enfocado en puestos a cubrir por jóvenes estudiantes o recién graduados, sin o con poca experiencia.

- Asociaciones y colegios profesionales:

- Anuncios de prensa: La empresa comunica las necesidades de personal a un amplio público. Incluye las publicaciones en diarios y revistas especializadas. Para este tipo de búsqueda, debe hacerse énfasis en la elaboración del anuncio, los tipos de anuncios y la eficacia que se busca del mismo y el costo. Hasta hace unos años, era uno de los medios más utilizados.

\section{Ventajas y desventajas del reclutamiento externo.}

Las ventajas que Giacomelli Treviño (2009)destaca, son la importación de nuevas experiencias en la organización, renueva y enriquece los recursos humanos de la organización, en especial, cuando la política es recibir personas que tengan la misma idoneidad o mayor que la que hay en la empresa y aprovecha la inversión en capacitación y desarrollo de personal efectuados por las empresas o por los propios candidatos.

Las desventajas, son sobre todo en costos, inversiones y gastos que se pueden producir a la hora de querer llevar a cabo un procedimiento de reclutamiento externo (avisos, entrevistas, preselección, etc). Es menos seguro que el reclutamiento interno, porque estamos hablando de personas desconocidas para la organización y que no podemos verificar con exactitud sus trayectorias profesionales.

\subsection{SELECCIÓN DE PERSONAL: DEFINICIÓN Y CARACTERÍSTICAS}

Para Chiavenato (2001) La tarea básica de la selección es escoger entre los candidatos reclutados aquellos que tengan mayores probabilidades de adaptarse al cargo ofrecido y desempeñarlo bien. 
La selección busca solucionar dos problemas fundamentales:

- Adecuación del hombre al cargo

- Eficiencia del hombre al cargo

Las personas difieren tanto en la capacidad para aprender a realizar una tarea como en la ejecución de ella, una vez aprendida. Calcular a priori el tiempo de aprendizaje y el rendimiento en la ejecución es tarea de la selección

Podemos mirar a la selección como

Un proceso de comparación: ya que compara los requisitos del cargo y el perfil de las características de los candidatos que se presentan. La primer variable la suministran el análisis y la descripción del cargo; la segunda se obtiene mediante la aplicación de técnicas de selección.

Un proceso de decisión: una vez establecida la comparación entre las características exigidas por el cargo y las de los candidatos, puede suceder que varios de ellos cumplan las exigencias y merezcan ser postulados para que el organismo solicitante los tenga en cuenta como candidatos el cargo vacante. La decisión final de aceptar o rechazar los candidatos es siempre responsabilidad del organismo solicitante. De este modo, la selección es responsabilidad de línea y función de staff.

Como proceso de decisión, la selección de personal implica tres modelos de comportamiento:

a) Modelo de colocación: el candidato presentado debe ser admitido sin objeción alguna.

b) Modelo de selección: cuando hay varios candidatos para cubrir una vacante. Cada candidato se compara con los requisitos que exija el cargo por proveer; pueden ocurrir dos alternativas: aprobación o rechazo.

c) Modelo de clasificación: Hay varios candidatos para cada vacante y varias vacantes para cada candidato. Cada candidato se compara con los requisitos exigidos para ocupar el cargo vacante. Ocurren dos alternativas para el candidato: puede ser rechazado o aceptado para ese cargo. Si es rechazado, pasa a ser comparado con los requisitos exigidos para los otros cargos vacantes, hasta que éstos se agoten; de ahí la denominación de clasificación 
La empresa no lo considera dirigido a determinado cargo, sino como un candidato de la organización que será ubicado en el cargo más adecuado a sus características personales.

\subsubsection{Bases para la selección de personas}

La herramienta fundamental para la selección de personal, es el análisis y descripción del puesto, que, según Dessler (2009) es un procedimiento para establecer las obligaciones y las habilidades que requiere un puesto, así como el tipo de persona que se debe de contratar para ocuparlo.

Dicho análisis, según Chiavenato (2001), se realiza a través de observación directa, entrevistas con el personal que realiza el puesto y sus superiores. De esa forma, se establece no sólo lo que se espera de la tarea en sí (el contenido del cargo) sino también las características que debe tener el aspirante al puesto.

En el caso de que el puesto sea nuevo, el mismo autor sugiere hacer un análisis del cargo en el mercado, es decir, observar en empresas similares, el puesto que se requiere, el contenido y los requisitos.

\subsubsection{Elección de las técnicas de selección.}

Para Chiavenato (2001), las técnicas elegidas deben representar el mejor elemento de predicción para un buen desempeño futuro en el cargo. El mismo autor define a un predictor como:

"La característica que debe tener una técnica de selección para predecir el comportamiento del candidato, con base en los resultados alcanzados al ser sometido a esa técnica."

Es necesario remarcar que puede utilizarse una o varias de las técnicas que serán presentadas a continuación, según la necesidad y tipo de puesto que se está buscando.

a) Entrevista de selección: Es uno de los métodos mayormente utilizados en la selección de personal y uno de los más antiguos. Se calcula que en todos los procesos de selección esta técnica puede utilizarse, de una u otra manera. Según Perea Rivera (2006) tiene las siguientes formas de utilización en un proceso de selección como: 
1- primera entrevista o entrevista técnica. Generalmente, realizada por el supervisor directo o el jefe de la vacante a cubrir, tiene como objetivo, verificar la aptitud o conocimiento del postulante y evaluar si cumple con los requerimientos del puesto.

La primera entrevista también puede realizarse de manera telefónica para corroborar algunos datos del cv y poder indagar acerca del postulante y coordinar una entrevista personal.

2- entrevista psicológica. Es decir, la evaluación del candidato realizado por un psicólogo.

3- Entrevista de selección o entrevista final. Se utiliza cuando el proceso de selección está por finalizar y es necesaria otra evaluación del candidato para poder decidir si se incorpora a la organización o no.

b) Pruebas de conocimiento o de capacidad: son instrumentos para evaluar con objetividad los conocimientos y habilidades adquiridos mediante el estudio, la práctica o el ejercicio. Buscan medir el grado de conocimientos profesionales o técnicos exigidos por el cargo. Éstas pueden clasificarse en pruebas generales (sobre cultura o nociones generales) o específicas (indagan sobre conocimientos técnicos directamente relacionados con el cargo de referencia)

c) Pruebas psicométricas: conjunto de pruebas que se aplica a las personas para apreciar su desarrollo mental, sus aptitudes, habilidades, conocimientos, etc. Sirve para medir el razonamiento verbal, la inteligencia, etc. Del postulante que están latentes y pueden desarrollarse mediante la práctica.

d) Pruebas de personalidad: sirven para analizar diversos rasgos de la personalidad, sean determinados por el carácter (rasgos adquiridos o fenotípicos) o por el temperamento (rasgos heredados o genotípicos)

e) Técnicas de simulación: Método de pruebas basado en la medición del desempeño real en tareas laborales básicas.

Una vez analizados conceptualmente en qué consisten los recursos humanos, el enfoque de sistemas y la función de modo específico, así como también los aspectos básicos referidos al reclutamiento y la selección de personal, corresponde ahora enfocarse en las nuevas tendencias en la gestión de personas. 


\section{Capítulo III: NUEVAS TENDENCIAS EN LA GESTIÓN DE PERSONAS}

En este capítulo se hará referencia a las nuevas tendencias en la gestión de personas, que incluye aspectos tales como la gestión del conocimiento y del bienestar.

Ambas teorías, tienen en común que surgieron a partir de una nueva generación de trabajadores: los millenians. Esta generación, según Cuesta, Ibáñez, Tagliabue, \& Zangaro (2009), nacida entre 1985 y el 2000, tiene como ventajas por la multitarea, la adaptabilidad del uso de la tecnología y la orientación por objetivos; por el contrario, una de las principales desventajas es que es la generación con más falta de fidelización, debido a que sus principales intereses pueden resumirse en la búsqueda de desarrollo de la carrera, la formación y el tiempo de ocio.

Es por ello que las organizaciones están buscando nuevas formas de motivar a esta generación, alejándose de las teorías más tradicionales y que pueda contribuir al logro de los objetivos generales.

\section{1) FORMAS NOVEDOSAS DE GESTIONAR EL PERSONAL}

\subsection{Gestión del conocimiento:}

\section{Importancia}

Según Cabrera Izquierdo \& Rincón Hercules (2001), el conocimiento y el talento humano pasaron a ser la base del éxito en el siglo XXI. Así como en el siglo pasado los recursos necesarios para crecer y mantenerse eran las materias primas y la energía, actualmente se prioriza las formas de gestionar los recursos existentes, es decir, la creatividad para poder administrar los recursos que se tienen. Ya sea por la probable escasez de la materia prima y recursos energéticos o por el auge de las comunicaciones, el conocimiento y, por ende, el talento humano, pasan a ser claves para el cambiante mundo de hoy. En la actualidad, el conocimiento organizacional, es decir, la sumatoria de los conocimientos individuales sumado a la experiencia lograda en la sinergia organizacional, pasan a ser parte de una ventaja competitiva y de los activos intangibles que posee una organización.

Pereda Marin, Berrocal, \& Quero (2002) establecen un cambio en la pirámide organizacional.

El punto de vista clásico de la pirámide, ubica en la base a los clientes y tiene como sustento la jerarquía organizacional, siendo la cúspide el nivel estratégico. Si existiera un problema o un reclamo por parte del cliente, quien recibe la información es el nivel operativo debido a su cercanía. La comunicación escala en la pirámide organizacional y en el caso de que no sea resuelto por el nivel 
funcional, debe pasar por el nivel estratégico y luego descender, con toda su demora y costos que esto demanda.

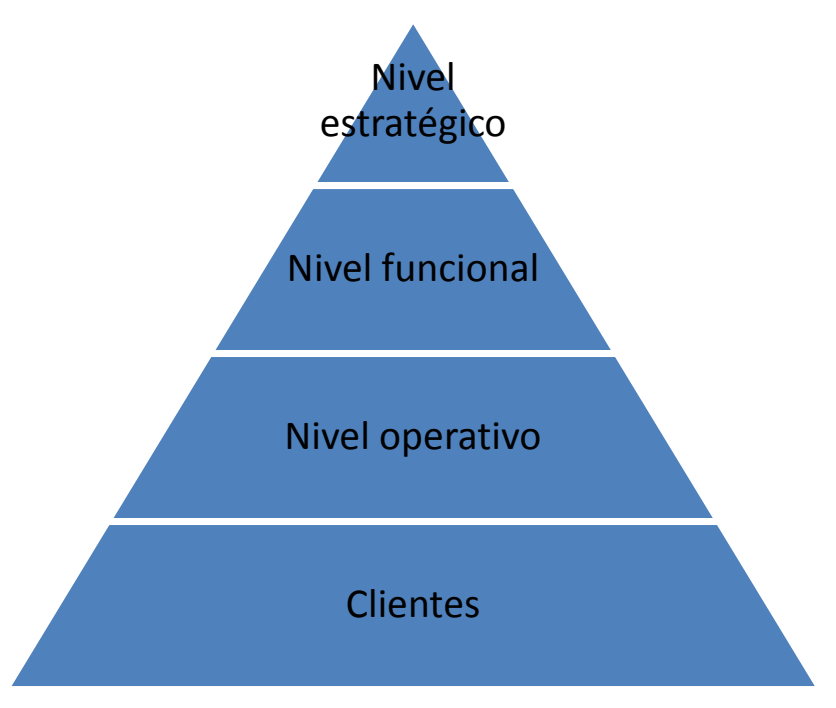

Nombre: pirámide organizacional clásica

Fuente: Pereda Marin, Berrocal, \& Quero, Gestión de Recursos Humanos por competencias y gestión del conocimiento (2002)

Los mismos autores plantean que hoy en día el cliente es el centro de atención de las organizaciones, debido a la alta competitividad. Para ello la organización debería reducir sus niveles jerárquicos y otorgar a sus empleados la suficiente autonomía para que, en caso del planteo de un problema o reclamo, sea posible que ellos mismos puedan darle una solución al cliente de manera más rápida. 


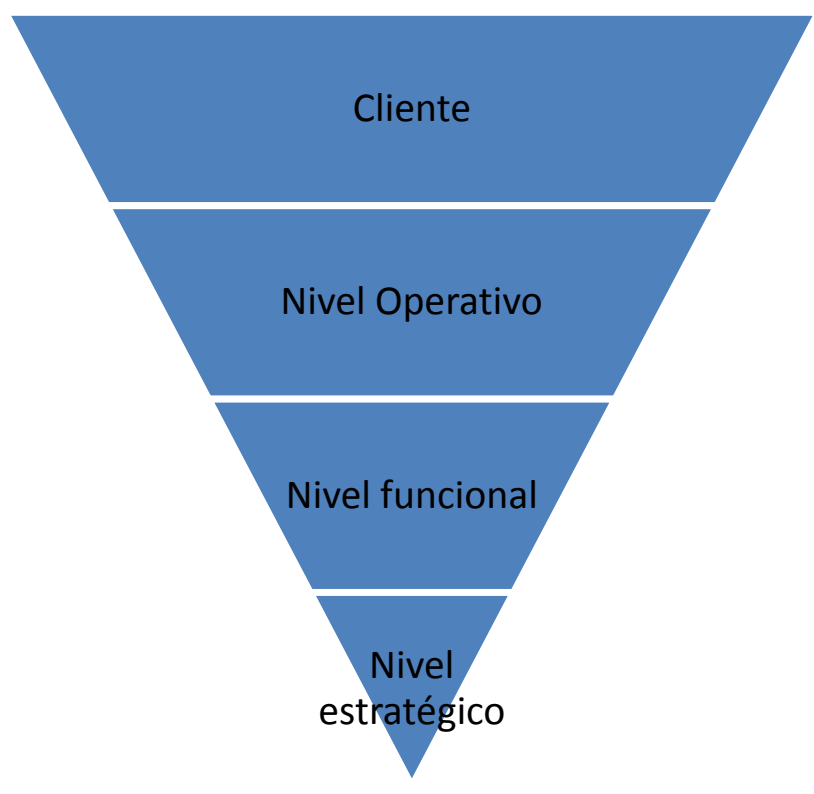

Nombre: pirámide organizacional invertida

Fuente: (Pereda Marin, Berrocal, \& Quero, Gestión de Recursos Humanos por competencias y gestión del conocimiento, 2002)

Retomando el tema de los modelos de conocimiento, los primeros autores en mencionar la importancia del mismo fueron, citando a Angulo Rincon(2017), Nonaka y Takeuchi (1995) cuando, al realizar un estudio en las compañías asiáticas, dieron cuenta del papel que la innovación ocupaba en las mismas. En ellas encontraron que el conocimiento debía ser, en principio, creado para luego ser esparcido a sus integrantes que luego podrían materializarlo.

\subsubsection{Hacia un concepto de conocimiento:}

Cuando se habla de conocimiento se hace referencia, según Nieves Lahaba \& León Santos (2001, pág 121) a

"Ias características internas y al comportamiento de un sujeto, tanto en las reacciones como en sus relaciones con los estímulos del ambiente", (...)"es una reflexión de todo lo que el ser humano ha aprendido, aplicado y organizado".

Podría describirse como la experiencia que ha tenido una persona ejecutando o realizando determinadas tareas, pero también comprende su reflexión, cómo internalizó esa herramienta y cómo puede aplicarla en otras situaciones.

Los mismos autores definen la gestión del conocimiento como 
"un proceso constante de identificar, encontrar, clasificar, proyectar, presentar y usar de un modo más eficiente el conocimiento y la experiencia del negocio, acumulada en la organización, de forma que mejore el alcance del empleado para conseguir ventajas competitivas".

\subsubsection{Características del conocimiento}

- es dinámico: según Cabrera Izquierdo \& Rincón Hercules, (2001), se intentó describir de manera expresa, a través del análisis y diseño de puestos, los conocimientos que necesita una persona para desempeñar diversos tipos de tareas, hoy por hoy, lo que una persona puede sumar en una organización va más allá e incluye tanto las habilidades como las intuiciones íntimas de cada individuo.

- Es social: es el resultado de un proceso de interacción de los individuos a través de las redes sociales. Esto quiere decir que el conocimiento que cada persona tiene por sí solo es valioso, pero aumenta su valor a medida que el mismo comienza a compartirse en el círculo social en el cual la persona está en la organización. En este sentido, Cabrera Izquierdo \& Rincón Hercules, 2001) ejemplifican que por más que un competidor se lleve a toda nuestra planta de personal a trabajar con él, no se puede replicar el sistema de gestión de la empresa (liderazgo, estructura, políticas, etc), es decir, el conocimiento colectivo tácito, que es el que verdaderamente es considerada la ventaja competitiva

\subsubsection{Tipos de conocimiento}

Cabrera Izquierdo et al (2001) realizan la siguiente clasificación del conocimiento:

- Conocimiento explícito o declarativo: es el conocimiento que se encuentra en un manual de funciones para realizar una tarea o serie de saberes adquiridos por un proceso de formación, por ejemplo, las buenas prácticas de venta de una empresa.

- Conocimiento tácito o procedimental : surge de la reflexión de las tareas una vez realizadas. Por ejemplo, un consejo para poder tratar con un tipo de proveedor. Es el más difícil de transmitir.

\subsubsection{Modelos de la Gestión del conocimiento}

Estos conocimientos no son estáticos; se encuentran en constante interacción mediante las siguientes relaciones 
- Del conocimiento explícito al tácito: éstos se relacionan mediante la compilación generada por rutinas de trabajo o de acciones. Un ejemplo podría ser un empleado ha recibido las instrucciones para operar determinada maquinaria y puede hacerlo sin cometer errores

- Del conocimiento tácito al explícito: por medio de la articulación, se comunican habilidades personales para ejercitar, por ejemplo, las buenas prácticas de ventas

- Del conocimiento tácito a tácito: se verifica gracias a la socialización. Una persona que se desempeña en un nuevo puesto de trabajo, aprende de sus pares y entre ellos, pueden intercambiar experiencias de forma verbal.

- Del conocimiento explícito al explícito: se encarga que la difusión de una buena práctica laboral llegue a toda la empresa y personas de la misma, mediante los canales de comunicación existentes.

Si se tiene en cuenta el carácter social del conocimiento, es necesario mencionar el conocimiento colectivo, que es el que surge de la combinación de los saberes de las personas que forman parte de la organización: esto no es sólo la suma de sus partes, sino que es superior y surge de la interacción con otros.

Teniendo en cuenta el análisis anterior, se puede decir que existen cuatro tipos de conocimientos, graficados de la siguiente forma

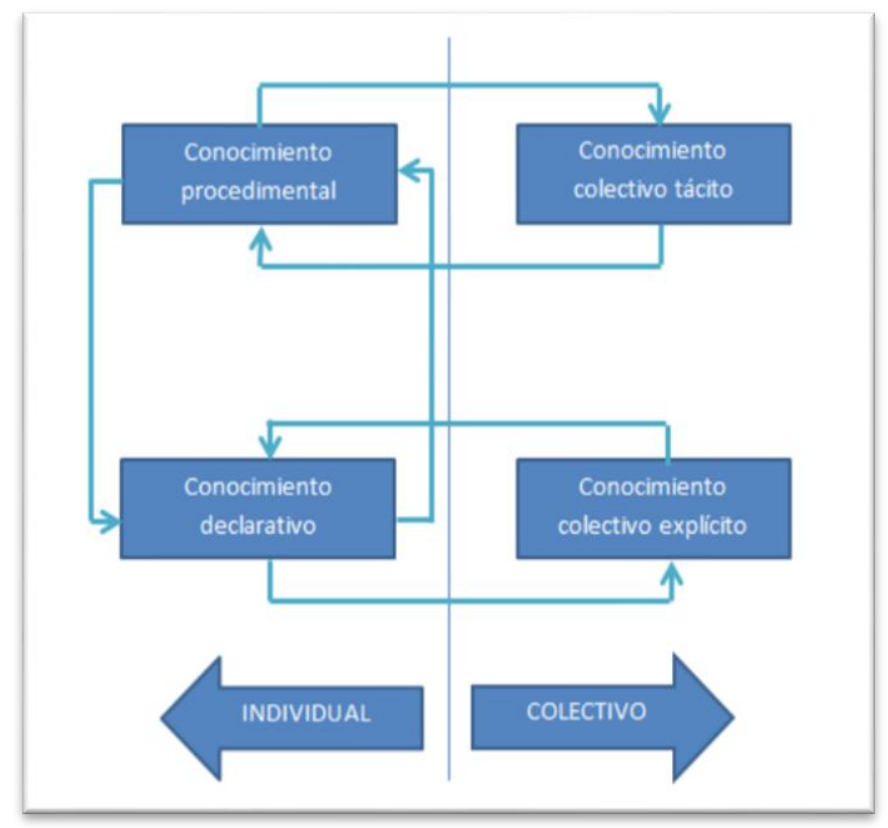

Nombre: Tipos de conocimiento

Fuente:Cabrera Izquierdo \& Rincón Hercules (2001) 
- Conocimiento colectivo explícito: por ejemplo, el estado de cuenta de un proveedor, sus medios de pagos más frecuentes y las características más relevantes de su servicio, como fechas de entrega.

- Conocimiento colectivo tácito: es el más difícil de imitar ya que surge de la interacción social de los individuos y pueden o no estar escritos. Tienen que ver con lo que "se sabe" de un cliente, por ejemplo, el tipo de servicio que se le brinda, las características de puntualidad y respuesta a un cliente.

\subsubsection{Relevancia del conocimiento en la gestión de personas}

La gestión de personal y de conocimiento están relacionadas ya que ambas comparten objetivos comunes, según Macias Gelabert \& Aguilera Martinez (2012).

La gestión de personal y de conocimiento están relacionadas ya que ambas comparten objetivos comunes. Svetilk \& Stavrou Costea (2007) en Macias Gelabert \& Aguilera Martinez, (2012 p. 139), ésta relación también puede verse en las fases de la gestión del conocimiento y del sistema de gestión de recursos humanos:

“1) Adquisición de conocimiento. Incluye el reclutamiento, la selección de personas con elevado capital humano y la contribución de su aprendizaje y crecimientos continuos, así como la motivación a las personas a participar dentro de las redes profesionales y comunidades de práctica

2) Creación de conocimiento. Se logra estableciendo un entorno de apoyo a los individuos, grupos y equipos de trabajo y la inversión en formación y desarrollo del capital humano existente en la empresa.

3) La diseminación del conocimiento. Contribuye al aprendizaje y la creación de un clima de cooperación en la organización, y esta se logra a partir de la evaluación de necesidades y la implementación de acciones de formación y desarrollo.

4) La aplicación del conocimiento. Se relaciona con la utilización del capital humano en las actividades cotidianas lo cual se logra a través de la efectividad en el liderazgo, en la división de trabajo, de los sistemas de compensación y de la evaluación de desempeño" 


\subsection{Dirección por valores}

\subsubsection{Definición de valor}

Siguiendo a Toniut et al. (2015) quienes citan a Garcia y Dolan (1997) para definir a un valor como

"es una convicción o creencia, estable en el tiempo, de que un determinado modo de conducta o una finalidad existencial es personal o socialmente preferible a su modo opuesto de conducta o a su finalidad existencial contraria"

Es muy importante tener en cuenta el contexto en el cual está inmersa la organización ya que de esto depende de los valores que sean preponderantes en la misma. (Toniut, et al., 2015) Señalan que "cada sociedad o cultura forja sus propios valores en virtud de las relaciones que se establecen entre los individuos y las apreciaciones que estos realizan"

\subsubsection{Definición de dirección por valores}

Toniut et al (2015) Citan a Salvador García (2011) y definen a la gestión de valores de la siguiente forma:

"la gestión de valores es una legitimación, diseño, puesta en práctica y evaluación de un proyecto participativo de formulación de la visión, misión y los valores instrumentales para alcanzar la visión, cumplir con la misión, con un equilibrio de valores tanto económicos, éticos y emocionales.

Lo que se busca es una coherencia entre lo establecido como misión y visión en la organización con los procesos y actividades que desarrollan los trabajadores.

\subsubsection{Implementación}

Toniut, et al (2015), citando a Ken Blauchard y MIcheal O'connor (1997), expresan una forma de implementar la gestión por valores

Fase 1: Aclarar la misión y los valores. 
Como primera medida, la junta directiva o los propietarios de la organización establecen cuáles son los valores de la organización y a partir de esta definición, surge el concepto de misión.

Esta información debe ser evaluada por los empleados, primero para saber si se sienten representados y segundo, si sirve como guía a aplicar en las actividades de la organización.

Luego, clientes, proveedores y otros grupos de interés, tendrán la posibilidad de evaluar y convalidar o no, los valores propuestos.

\section{Fase 2: Comunicación}

Se informa cuáles son la misión y los valores resultantes del proceso anterior y la capacidad de éstos para que sirvan como guía en la realización de las tareas; esto será posible si todas las partes involucradas asumen un verdadero compromiso.

\section{Fase 3: Alineación}

Se busca que los valores se vean reflejados en las prácticas de trabajo de todas las personas en la organización, así como también en los sistemas, recursos humanos, la administración y otros grupos de interés.

El objetivo de este punto es establecer un plan de mejora continua para verificar que todas las actividades están siendo coherentes con los valores propuestos.

\subsubsection{Cuál es la importancia.}

Para Dolan y Garcia (2000), en la aparente turbulencia en el contexto del comercio internacional, los increíbles saltos tecnológicos, el fenómeno de inestabilidad política" los valores se convierten en un ideal a alcanzar por los líderes de la organización y sirven como guía para las actividades de las personas en la organización.

\subsubsection{Por qué aún falla este modelo de gestión}

Según Toniut et al (2015), las principales desventajas que tiene la aplicación del modelo de gestión de valores son:

- Mala definición de valores: se definen valores deseables y no los actuales o que no son fácilmente de relacionar con el desempeño laboral

- Se asume que rápidamente la organización se amoldará al nuevo sistema 
- No son considerados por el resto de la organización

- No son utilizados en la toma de decisiones de la política organizacional y en la empresa.

\subsection{Gestión del bienestar}

Citando a Laca Arocena, Mejías Ceballos y Gondra Rezola (2006), tradicionalmente la psicología organizacional estudiaba aquellas patologías que disminuían el desempeño laboral y provocaban por ejemplo el ausentismo laboral. La bibliografía principal de la psicología organizacional, enlista las enfermedades que se pueden padecer, pero no así, aquellas situaciones o contextos en los cuales se puede desarrollar el bienestar.

Salanova, Martinez, \& Llorens (2014) definen a la psicología organizacional positiva como:

"estudio científico del funcionamiento óptimo de la salud de las personas, de los grupos en las organizaciones, así como la gestión efectiva del bienestar psicosocial en el trabajo y del desarrollo de las organizaciones para que sean más saludables"

El interés sobre la salud y el bienestar de los empleados ha pasado a ocupar un mayor lugar en las organizaciones, dando origen al concepto de organización positiva: son aquellas que, además de buscar la obtención de ganancias y la satisfacción del cliente, tienen como objetivo lograr la salud física y mental de los empleados y, también, ser capaz de mantener un ambiente y cultura organizacional saludables, en especial en tiempos de crisis.

\subsubsection{Un modelo de bienestar organizacional: corazones at work}

Si bien cada vez más las empresas están interesadas en la aplicación del bienestar organizacional, existen también varios modelos para la medición del mismo. Uno de ellos es Corazones at work, desarrollado por la empresa Big Bienestar. El mismo cuenta con las siguientes etapas:

1) Top Down: una decisión del alto nivel

El primer paso para la mejora en el bienestar organizacional es la decisión en tal sentido por parte de los altos mandos. Es necesario que no sea sólo un departamento más en Recursos Humanos, sino parte de la estrategia organizacional, ya que le brinda coherencia, convicción y credibilidad al resto del proceso. La dirección de la organización puede o no estar en una situación de bienestar, sino que deben y tienen que estar comprometidos para participar en el proceso. 


\section{2) Corazones}

Son los ejes a través de los cuales puede medirse el bienestar organizacional y pueden subdividirse en:

- Económico: incluye las condiciones de trabajo y la puesta en valor. El sueldo real, emocional o intelectual que recibe una persona. Va mas allá del sueldo monetario, sino que además, incluye los otros beneficios que permiten un equilibrio entre la vida familiar y la laboral (por ejemplo, las guarderías o jardines maternales, el regalo de útiles para el colegio de los empleados, posibilidad de capacitaciones y crecimiento profesional.

- Entorno: está integrado por el clima organizacional y el bienestar subjetivo. Son las relaciones, las políticas, la cultura y la gestión de personas que caracterizan a la organización y cómo impactan en las personas y en su desempeño laboral.

- Estabilidad: la confianza en la organización y entre sus colaboradores. Para ello, es importante analizar las expectativas futuras, teniendo en cuenta la actual y las pasadas.

- Empatía: hace referencia a la comunicación y las relaciones saludables. Aquí se busca lograr una sinergia entre las distintas generaciones que pueden coexistir en una organización.

- Evolución: la capacidad de la organización de adaptarse a los cambios del contexto a través de sus líderes y colaboradores.

- Engagement: es el compromiso que la misma organización genera para con sus miembros.

Estos ejes son medidos a través de cuestionarios personales y con carácter confidencial, realizados a todos los miembros de la organización.

3) Medición

Se realizan entrevistas a grupos de interés de 15 a 20 personas. Estos encuentros, junto al resultado de los cuestionarios personales, dan un diagnóstico de la situación actual de la organización.

4) Informe

Una vez recabada y procesada toda la información de las etapas anteriores, se elabora un informe que se presenta a los líderes, directivos e interesados, con el fin de mostrar en qué situación se encuentra la organización y cuáles serían las mejoras a aplicar.

\subsection{2 ¿Por qué es importante?}


La gestión por bienestar se destaca por ser la nueva tendencia en gestión del personal. Aún es muy reciente analizar cuáles serían las ventajas y desventajas de su aplicación, ya que no existe, en principio, un único modelo para poder implementar y medir esta manera de gestión de personal. Por otra parte, es importante aclarar que se trata de un modelo de gestión que está en su primera etapa, es decir, falta aún recolectar más evidencia sobre el resultado del modelo.

En este capítulo se abordó el tema de las nuevas tendencias en la gestión del recurso humano, dos modelos que intentan explicar el nuevo paradigma de la motivación en el trabajo con respecto a las nuevas generaciones. De este modo, en el próximo capítulo, corresponde analizar cuáles son las nuevas técnicas que se utilizan para reclutar y seleccionar personal. 


\section{Capítulo IV: LAS NUEVAS TÉCNICAS DE RECLUTAMIENTO Y SELECCIÓN}

Corresponde tener en cuenta, dado el avance del trabajo, las nuevas técnicas de reclutamiento y selección de personas, dado que anteriormente ya se ha analizado las técnicas anteriores y el nuevo paradigma en la gestión de personas.

En el presente capítulo, se explicará la atracción de personas, el reclutamiento y selección de personal con las herramientas 2.0 que hoy están disponibles o en desarrollo.

\section{1) ATRACCIÓN DE PERSONAS}

Martha Alles (2013) explica que antes de reclutar y seleccionar personas es necesario atraerlas a la empresa u organización; es decir, generar interés a las personas más adecuadas a cubrir los puestos de la empresa. Para ello, propone definir acciones con las áreas de marketing, relaciones corporativas e imagen corporativa, y crear así la marca empleadora/marca del empleador, que no es más que construir una imagen positiva del mercado laboral hacia la empresa y que la gente desee trabajar en la misma.

Esto no es ninguna novedad, ya que los procesos de reclutamiento y selección siempre han sido bilaterales. Es decir, se puede analizar el proceso, desde el punto de vista del aspirante al puesto y desde el punto de vista de la empresa, tal como expresan Morrell Blanch y Brunet Icart (1999), citando a Alcaide, González, y Florez (1996):

Desde el punto de vista del individuo $u$ aspirante al puesto:

a) "trata de atraer a las organizaciones mostrándose atractivo dentro del proceso de reclutamiento - selección, lo cual intenta a través de la información que suministra la empresa, adoptando su comportamiento durante el proceso de selección a los que piensa que son los deseos de la empresa"

b) "el individuo también selecciona organizaciones. Las preferencias de aquél por una u otra empresa se forman a partir de la información que el sujeto acumula y que obtiene de muy diversas fuentes; anuncio de reclutamiento, publicidad general de la empresa, a través de empleados, etc".

Desde el punto de vista de la empresa: 
a) "Ia organización trata de atraer individuos, mostrándose atractiva en el mercado de trabajo con el propósito de obtener un número suficiente de candidaturas idóneas"

b) "la organización selecciona a los individuos, con el propósito de identificar a aquellos que mejor se adecúen a los requisitos definidos por ésta. En este empeño, la empresa utiliza diversas técnicas o instrumentos para obtener información de los candidatos, tales como, por ejemplo, la entrevista, los test piscotécnicos y otras pruebas de selección"

\section{1 ¿Qué es la marca empleadora?}

Según Perez García (2016), una marca empleadora es una opción innovadora a la búsqueda de talento, mucho más duradera a través del cual los aspirantes al puesto se dirigen a la empresa sin necesidad de publicar una vacante a un puesto.

\section{2 ¿Por qué utilizarla?}

Siguiendo a Esteban (2012), los argumentos para utilizarla son varios; Se pueden explicitar de la siguiente manera:

1) Debido a la crisis de empleo y de las personas, las marcas empresarias son importantes. Los cambios en las fuerzas económicas de los últimos tiempos sugieren que la empresa es responsable de generar las condiciones para que los empleados se sientan identificados entre sus valores y las empresas en las que trabajan.

2) Las marcas empresarias crean y mantienen culturas fuertes, ideales para poder sobrellevar las crisis actuales.

3) Necesidad de gestionar los riesgos. Esto hace énfasis en el poder que tienen hoy por hoy las redes sociales y el papel que los empleados como embajadores de marca, pueden tener en el público que consume el producto. Dice Esteban (2012)

(..) "no hay mejor prescriptor - ni campaña de marketing más barata- que el cliente fiel y satisfecho o el empleado con orgullo de pertenencia".

\section{2) RECLUTAMIENTO 2.0}

Alles (2003) define al reclutamiento como: 
"Conjunto de procedimientos para atraer e identificar a candidatos potencialmente calificados y capaces utilizando las posibilidades de la web 2.0 a través de:

- Publicar oportunidades para obtener postulaciones.

- Ofrecer posibles puestos de trabajo a personas que no están buscando trabajo de manera activa.

En todos los casos, las acciones propuestas tienen a identificar a posibles candidatos para ocupar el puesto ofrecido, a fin de seleccionar alguno/s de ellos para que reciban el ofrecimiento del empleo"

Los caminos para poder realizar esta actividad es

a) Que el reclutador forme parte de diversas redes sociales e ir agendando contactos. Cuando una búsqueda sea necesaria, contactarlos.

Esto suele utilizarse mucho en redes como LinkedIn, los reclutadores van aceptando gente en sus contactos $y$, al necesitar un perfil determinado, publican la oferta Muchos de ellos pueden realizar dos cosas: o pedir directamente que envíen el cv o sólo con ver los perfiles es suficiente para la evaluación del puesto. Generalmente, suelen pedir el envío del cv a una casilla de correos, lo que puede provocar la llegada masiva de correos y no un correcto análisis de los mismos.

b) Solicitar candidatos a los contactos que tiene en la red.

Es decir, poner una publicación en estado público para "recomendar" o "compartir" y que los contactos lo viralicen. Si se conociera a la mayoría de los contactos que uno tiene en una red, podría funcionar como una forma de recomendación y hasta pedir referencias. En el caso que no sea así, podría producirse lo mismo que en el punto anterior: una gran cantidad de correos con cv que pueden o no tener con el puesto buscado, que hace perder el tiempo del reclutador.

c) Head hunting: rastrear dentro de las redes sociales, teniendo en cuenta ciertos parámetros y solo a personas que cumplan con ellos y ofrecerles participar del proceso.

Los head hunter son cazadores de talentos. Se realiza una búsqueda por redes sociales (en general LinkedIn), sobre determinados perfiles, en general, buscan personas que estén ocupando un puesto similar al buscado en una empresa con similares características a la que realiza la búsqueda. Para ello, no sólo son necesarias las habilidades de reclutamiento de personal o leer un perfil correctamente, sino persuasión y venta de la oferta laboral. 
- Las nuevas fuentes de reclutamiento:

Según Andrés Reina (2004), las fuentes de reclutamiento on line pueden clasificarse en las siguientes:

a) Las web corporativas

Las páginas web de las empresas suelen ser fuente para que las personas dejen su correo electrónico o rellenen los campos de un formulario dejando sus datos. Esto origina una gran base de datos digital, que puede resultar tediosa de revisar, y puede realizarse una clasificación de los curriculums y candidatos registrados, dependiendo su formación, experiencia laboral.

Esta forma de reclutar personal, depende mucho de la imagen corporativa que se haya generado en las personas, es decir, que los candidatos tienen que sentirse atraídos a la empresa por su trayectoria y la gestión de RR.HH que suelen mostrar via web.

b) Portales de Empleo

Los portales de empleo son empresas especializadas en atraer candidatos laborales, las mismas publican los datos de las búsquedas que realizan otras empresas, a cambio de dinero. Tienen distintas tarifas y también dependen de la referencia que tengan los candidatos sobre ellas.

Se pueden mencionar las siguientes como las más populares en Argentina son:

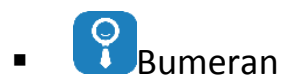

En la actualidad tiene alrededor de 6.000 ofertas de empleo activas. Se puede filtrar avisos de trabajo según provincia, localidad, área de trabajo, y también nivel laboral deseado.

\section{- JonaJobs}

ZonaJobs es una de las empresas más reputadas de Latinoamérica en lo referente a búsqueda de empleo. Tiene su portal activo en 6 países de Latinoamérica, entre los cuáles se encuentra Argentina. Empresas de reputación probada dejan sus anuncios en ZonaJobs, más de 150.000 en total. 


\section{- $\stackrel{\mathbf{C T}}{=}$ Computrabajo}

En su propia web afirma ser el portal con más ofertas de trabajo de Argentina, casi 30.000. Lo mejor de todo de esta página web, además de su gran volumen de ofertas, es que posee una interfaz muy simple, atractiva y funcional. En la página de portada ya puedes encontrar el número de ofertas existentes y verlas divididas según su área de especialización o la localización del puesto de trabajo ofertado.

\section{- Workana}

Es un portal para freelancers ${ }^{1}$. Publica un proyecto, y elige entre las propuestas que más te gusten de entre los profesionales que se postulen. Un portal tanto para empresas, como para nuevos emprendedores o profesionales autónomos. Principalmente, es una web destinada sobre todo a profesionales relacionados con las TIC: diseñadores, programadores, redactores, expertos en SEO, community managers, etc.

c) Redes Sociales:

García Castro, et al., (2016) definen las redes sociales como:

"Son los servicios que se ofertan a través de internet y que permiten a los usuarios generar un perfil público con información personal; proporcionan herramientas que permiten interactuar con otros usuarios y localizarlos en función de las características publicadas en sus perfiles."

Según los autores antes mencionados, las redes sociales, pueden clasificarse en:

a) Generalistas: su objetivo es facilitar y potencias las relaciones personales entre los usuarios.

- $f$ Facebook

Actualmente, Facebook agregó a sus funcionalidades la opción de "Empleos" la que permite publicar ofertas de trabajo y postularse a través del perfil en la aplicación.

La misma, filtra las vacantes de empleo por ubicación y da la opción de filtrar por sector y tipo de empleo.

\footnotetext{
${ }^{1}$ Freelancers: trabajadores por su propia cuenta.
} 
Una vez que el interesado desea postular, solo brinda los datos de contacto (Nombre, apellido, correo electrónico) y la experiencia laboral que se haya subido a su perfil, sin prestar consentimiento a que se revisen fotos y publicaciones personales a través de esta opción.

Si bien esta funcionalidad en Facebook es nueva, anteriormente se estaba utilizando grupos de búsquedas de trabajo donde personas y empresas intercambiaban búsquedas laborales 0 postulaciones espontáneas para quien lo necesitara, (sólo requiere la aceptación en el grupo por parte del administrador).

También, dentro de las herramientas que la aplicación tiene, está la de publicidad, en la cual se permite la publicar imágenes de distintos productos, en el que puede estar también las ofertas laborales, a través de una pauta y permite la segmentación del público al que va dirigido (especialmente por zona y edad)

b) Profesionales: búsqueda selectiva de candidatos, crean grupos de interés y amplían las redes de contactos profesionales.

- in Linkedln

Linkedin es la red social destinada al ámbito laboral, en la cual sus usuarios suben su curriculum vitae e interaccionan con pares o con reclutadores de personal de distintas empresas. La novedad que presenta esta red social es que, además de subir el curriculum, permite que otras personas dejen recomendaciones sobre el desempeño laboral (ex colega de trabajo, ex compañeros de facultad, etc) y da lugar a crear una red de contactos.

Actualmente, Linkedin se está consolidando como herramienta para la búsqueda de personal, permitiendo la creación de anuncios de empleo y páginas a las empresas, a cambio de una tarifa. Como potencial candidato, también se puede pagar una membresía que facilita las postulaciones, figurando entre los primeros curriculums que reciba la empresa. A su vez, esta red social facilita la búsqueda de perfiles potenciales a través de su buscador: allí se puede especificar qué puesto se está buscando, y da como resultado perfiles que ocupan puestos similares en otras empresas.

Los productos que ofrece Linkedin pueden resumirse en los siguientes:

Learning: plataforma de capacitaciones. Incluye desde cursos para aprender a usar determinado nivel de Excel, hasta fundamentos en la programación de sistemas. 
$\checkmark$ Publicitar: la plataforma que permite publicar anuncios sobre la marca en la red social.

$\checkmark$ Linkedin Recuiter: crea los anuncios de búsqueda de personal y ordena los perfiles postulados.

$\checkmark$ Profinder: trabaja ofreciendo proyectos a los cuales los freelancers pueden postularse.

$\checkmark$ Lookup: busca a las personas con el mismo dominio de correo empresarial. Sirve para conectar personas de empresas grandes que se encuentran en distintas partes del mundo.

Para facilitar su uso, la red social brinda servicios empresariales, tales como Talent Solutions (enfocado en los RR. HH), Sales Solutions (enfocado en las ventas) y Learning Solutions (enfocado en las capacitaciones de las empresas)

c) Verticales. Búsqueda directa según especialización, por ejemplo INNOCENTIVE, un sitio web que convoca a empresas privadas y usuarios, donde se comparten soluciones tecnológicas a determinados problemas, con una recompensa para estos últimos. Empresas como P\&G y Nestlé forman parte de esta red.

d) Otras. Redes de microblogging o nanoblogging. Publican ofertas laborales de forma gratuita, como Twitter.

Las ventajas y desventajas en el uso de las redes sociales son descriptas por (Gonzalez Sabín, 2005) y mencionadas por García Castro, et al., (2016):

\section{Ventajas:}

- Permiten segmentar el público objetivo al que va dirigida la oferta laboral

- Los medios sociales amplían el acceso a un enorme grupo de candidatos

- Existe disponibilidad de la oferta de trabajo de manera ilimitada

- Son de amplio alcance, ya que permiten reclutar personal de cualquier parte del mundo.

- Permiten disminuir costos

- Disponen de mayor información para los candidatos.

- Facilitan el proceso, ya que se procesa la información de manera electrónica

- Mantiene la base de datos sobre candidatos potenciales para futuros procesos de contratación 
- Permiten la consulta eficaz, ya que en el momento deseado se puede acceder al sistema de ofertas laborales.

- Forman parte de las funciones estratégicas de RR.HH

\section{Desventajas:}

- Saturación de candidaturas, generando gran cantidad de demanda de empleo.

- Pérdida de contacto humano

- Algunos sites de empleo no son tan eficientes para el filtrado de candidatos, dificultando la tarea para el seleccionador.

- No todos tienen la posibilidad de acceso, ya que algunas personas no poseen o no conocen el manejo de las herramientas tecnológicas.

- Falta de confiabilidad en el uso de los datos

- Muchos de los candidatos no poseen el perfil deseado.

- Limitaciones de las propias redes, ya sea por escasez, cobertura o mal funcionamiento.

- Algunos de los formatos que ofrecen los websites especializados son incompletos o desorganizados, complicando la tarea de selección

- La selección de personal es especialmente útil para determinados perfiles y puestos de trabajo, principalmente para puestos técnicos y no para puestos directivos

\section{3) LOS SOFTWARE DE RECURSOS HUMANOS}

Las oficinas de recursos humanos han pasado de ordenar la información de los curriculums y legajos en papel a llevar programas de computación capaces de organizar los procesos de reclutamiento, selección, así como también el historial de un empleado en la organización.

Los Software HCM (human Capital Management) es definido por Onofre, (2016) como

"un software en gestión de Talento Humano que colabora en los diferentes procesos administrativos de cualquier empresa que tenga a su cargo un personal" 
Los mismos, facilitan la recolección de los datos relacionados con el talento humano de la organización; los procesos principales que deben ser gestionados por un software de gestión de talento son:

1) Proceso de Ingreso de personal

2) Análisis y diseño de cargos

3) Compensación de personal

4) Capacitación del personal

5) Condiciones Laborales

6) Evaluación del personal

Enfocados en la etapa de Proceso de Ingreso de personal, estos software ayudan a revisar los curriculums, la filtración de los mismos, actualización de las bases de datos y la publicación de ofertas laborales.

Entre los más conocidos se encuentra Hiring Room, una plataforma gratis que permite publicar las vacantes en distintas redes sociales y páginas y visualizar el avance del proceso de selección, desde distintos dispositivos.

\section{4) SELECCIÓN}

Es la etapa en la cual se desarrollan los pasos, entrevistas y otras evaluaciones sobre los candidatos que pasaron la etapa anterior, de forma tal de determinar cuál es el más adecuado para cubrir la vacante.

\subsection{Nuevos métodos para la selección 2.0}

Los nuevos métodos para la selección 2.0 , no es solo la adaptación de las entrevistas y demás métodos a las herramientas tecnológicas, sino que también, puede verse un cambio en qué es lo que buscan los entrevistadores a la hora de sumar gente a sus empresas.

- Video conferencias

Las video conferencias o llamadas por whatapp, permiten la entrevista de personas sin que la distancia física sea un impedimento. Si bien el contenido de la entrevista puede ser el mismo que la 
entrevista personal, este tipo de reunión on line se considera un ahorro de tiempo para ambas partes y también permite grabar el encuentro y poder analizarlo posteriormente.

- Pruebas on line

Muchos reclutadores y empresas están utilizando las pruebas on line, que no es otra cosa que realización elaboración de cuestionarios múltiple opción donde se evalúan tanto aspectos de personalidad como de habilidades. Se los pone en uso muchas veces luego del primer filtro de candidatos y son muy similares a las pruebas que se realizaban con anterioridad con papel y lapiz. La ventaja que tiene este modo, es que no sólo el candidato puede realizarlo desde su pc sin ir al lugar de la entrevista, sino que permite al reclutador, hacer una comparación de los resultados entre los candidatos.

- La gamificación

Las nuevas tecnologías permiten la evaluación del candidato de otra forma: Según Galián Jimenez (2018), una de las herramientas en la gamificación, entendiendo por tal al proceso de evaluar el desempeño del candidato o las habilidades con las que cuenta y son necesarias para el puesto, a través de juegos o aplicaciones que se encuentran en el celular, diseñadas especialmente. Esto permite además, la comparación de los resultados entre los candidatos y una mejor adecuación del mismo a la empresa ya que también conocer si se puede adaptar a la cultura organizacional. Por otra parte, estas herramientas pueden utilizarse como complemento en las evaluaciones de desempeño

Este tipo de selección está surgiendo en España y otros países europeos, en aplicaciones como Knack, que permite la evaluación de las habilidades de los empleados y también el envío de los resultados a distintas empresas. Actualmente, Knack tiene entre sus clientes a varios centros educativos, marcas de ropa como Max Mara, empresas automotrices como Daimler y Tata Motors.

También, hay empresas que hacen sus propias aplicaciones para la búsqueda de personal, como el caso de Loreal que realizó la aplicación para ver en qué tipo de puesto podía adaptarse la persona .

- Inteligencia Artificial: el Robot Vera

Actualmente, se encuentra en estudio la incursión de inteligencia artificial en varios campos como la medicina, la industria y también las empresas, en especial, en el reclutamiento y selección de personas. 
La compañía rusa Strafory, creó a Vera, un robot tal como lo anuncian en su página web "podría ayudarte a encontrar los mejores candidatos". Este tipo de inteligencia artificial, se encarga de seleccionar curriculums, filtrarlos, llamar a los candidatos prospectos y hasta hacerles una entrevista utilizando una videollamada, siendo capaz de reconocer emociones en los entrevistados.

Hasta el día de hoy, esta aplicación ha sido utilizada en al menos 200 empresas, realizando aproximadamente 1.400 .000 entrevistas por teléfono y al menos 10.000 entrevistas vía video llamada.

En el capítulo anterior, se analizaron las nuevas técnicas en las tareas de reclutamiento y selección que se están utilizando o que están en desarrollo, según la bibliografía disponible. En el próximo capítulo, se analizarán la aplicación práctica de las mismas tanto en el ámbito internacional como en el local 


\section{Capítulo V: INFORME DEL TRABAJO DE CAMPO}

Con el objeto de validar el enfoque conceptual desarrollado en los capítulos precedentes, en este capítulo se expondrán los resultandos tanto de las entrevistas personales realizadas como de los informes que se encuentran en internet sobre el reclutamiento de personal.

\section{1) Informes internacionales}

Para este punto, se utilizó como fuente informes anuales de Linkedin (2018) y Adecco (2018). Los puntos más relevantes para este trabajo de investigación fueron los siguientes:

- Elementos a utilizar en el reclutamiento de personal:

A nivel internacional, según Adecco (2018) 97,88\% de los profesionales a cargo de un proceso de reclutamiento y selección utiliza portales de empleo. Un $94,7 \%$ usa contactos personales y un $72,44 \%$ utiliza redes sociales

- La utilización de la entrevista tradicional

En la actualidad, la entrevista cara a cara, por teléfono, grupal o individual, sigue siendo la principal herramienta que utilizan los reclutadores a nivel mundial según Linkedin (2018); a pesar de las desventajas que este método tiene en la evaluación de habilidades interpersonales, la identificación de las debilidades del candidato, el sesgo de los entrevistadores entre otros.

- La medición de habilidades blandas

A nivel internacional, también puede verse el uso de las audiciones de trabajo (resolución en equipo de problemas empresariales) y también entrevistar a las personas en un lugar fuera de una oficina (un restaurant, parque, café, etc) para crear un ambiente más relajado y pueden surgir imprevistos o situaciones ya planificadas que ponen de manifiesto ciertas actitudes del candidato que en otro ambiente sería muy difícil de evaluar.

\section{2) Entrevistas personales}

Se realizaron entrevistas a 5 referentes y especialistas dedicadas a los Recursos Humanos que trabajan en Mendoza. Se les solicitó, en una entrevista, que contestaran un cuestionario sobre las principales inquietudes de la gestión del personal, reclutamiento y selección. 
Los profesionales consultados, ocupan puestos en consultorías de RR.HH y tienen experiencia con empresas locales y algunos ocupan u ocuparon puestos en Gerencias de Recursos Humanos tanto de organizaciones sin fin de lucro como empresas. Incluye tanto Licenciados en Administración, psicólogos organizacionales y personales, con una experiencia en más de 3 años en la tarea de reclutamiento y selección de personal.

Con el objeto de ahondar en la caracterización de los entrevistados se agregan algunos datos que se consideran de interés, con la salvedad de resguardar su identidad, por lo cual se asignará una letra a cada entrevistado. Así, en el caso del Entrevistado A se trata de un consultor de Recursos Humanos, experto en capacitación y coaching quien se desempeña como socio director de una empresa especializada en entrenamiento y coaching de personas, con amplia experiencia en diversas empresas de alcance provincial y nacional, además de participar en un cargo directivo en una organización dedicada a la capacitación de personal ejecutivo.

El entrevistado B también es consultor en Recursos Humanos, experto en capacitación y coaching, director de una oficina internacional dedicada específicamente a la aplicación de metodologías 2.0, realizando tareas de consultoría.

En el caso del entrevistado C, se trata de una psicóloga clínica, organizacional y docente universitaria en universidades privadas y nacionales, consultora en Recursos Humanos en carácter independiente.

Con respecto al entrevistado $D$ es una psicóloga y docente universitaria, con amplia experiencia en consultoría sobre Recursos Humanos, habiéndose desempeñado en una Fundación dedicada al rubro.

Por último, en el caso del Entrevistado E estamos ante una analista especializada en Recursos Humanos que se desempeña en una empresa automotriz del medio.

En el Anexo A puede consultarse la guía de preguntas que se utilizó como eje para la realización de las entrevistas personales.

A continuación, se muestran los principales tópicos en los que los profesionales coincidieron:

- $\quad$ Formas de gestionar el personal: Mendoza y el modelo Homo œconomicus 
Si bien existe a nivel internacional mucha literatura al respecto de cuáles son las formas de gestionar personas, no hay un informe actual que permita conocer números de cuáles son las más utilizadas y cuántas organizaciones las emplean.

Tres de los cinco entrevistados afirmaron ver mejoras en la aplicación de cambios: El entrevistado B, quien está relacionado con la consultoría y el coach señala que los beneficios de estos nuevos métodos de gestión, pueden verse reflejados todas las organizaciones, sin importar el rubro y también expresan que no hay áreas o departamentos que se beneficien más o menos, pero el éxito depende del compromiso real que tenga la alta gerencia en mejorar la cultura organizacional. Mientras que las entrevistadas $A$ y $E$, vieron los beneficios en áreas y procesos específicos: planes de carrera y mejora en la productividad de la fuerza de venta.

En relación a este tema, una de las entrevistadas manifestó que "hay que saber diferenciar si es solo una moda, o realmente hay una visión donde toda la organización va a estar asumiéndola; porque otra cosa de las modas, es "compremos esto que es lo que se usa" "hagamos esto"; pero no hay un sustento detrás donde realmente la organización este comprometida con un verdadero cambio, sino que lo que quieren es limar una aspereza, quitarla, que todos se queden callados; un cambio superficial que pueda domar al empleado para que pueda hacer lo que uno quiere; entonces hoy están siendo cuestionadas muchas de las técnicas del management que fueron las nuevas teorías que lo único que lograron fue que el ser humano se quemara, trabajara más, se desgastara y no sirviera para otra cosa."

En Argentina y en especial, Mendoza, aún esta forma de gestionar personal, ante el predominio de las Pymes, las personas entrevistadas afirman que aún siguen utilizándose viejas prácticas en la gestión del personal, en concreto, las entrevistadas C y E no conocen organizaciones donde estos cambios se apliquen; por ejemplo, que la única forma de incentivar sea de forma monetaria o, en algunos casos, flexibilidad laboral para problemas personales que no se contemplen en la ley. A pesar de estos resultados, la entrevistada $\mathrm{C}$ reconoce que, con la nueva generación incorporada en la fuerza de trabajo (los millenians) las empresas se encuentran en un desafío, ya que las viejas formas de motivar, no causarían efecto en la generación mencionada. También, señala que aún deben esperarse los resultados de las nuevas formas de gestión y que no queden solo en un cambio superficial en la organización

Es así que un entrevistado expresa que "Hay organizaciones aquí en Argentina, en Mendoza misma donde aún está el pensamiento racional económico; en esas organizaciones, las nuevas 
teorías no pueden crecer porque ese propietario, fundador, considera que las personas que tiene trabajando operan con esa idea. Se da la famosa profecía autocumplida. Entonces, depende de la complejidad de la organización y de su apertura; van a poder desarrollarse y trabajarse estas nuevas teorías o nuevas formas de posibilitar del ser humano. Ante la complejidad del ser humano, puede lograr muchas cosas, así como también cometer los mismos errores, una, dos o más veces y si vos me preguntas, Freud decía que hay personas que fracasan cuando triunfan porque su propia personalidad los lleva a boicotearse, por temor al triunfo. Hay personas que se sabotean, no lo hacen conscientemente, eso se trabaja antes. Hay organizaciones donde parte de las nuevas teorías van a ser efecto y otras."

- $\quad$ El compromiso en los cambios organizacionales

El éxito de los cambios organizacionales, afirman tres de los cinco entrevistados, depende principalmente de las decisiones de gerencia y alta dirección. En efecto, los modelos planteados de gestión de personas en el presente trabajo, puede verse que, el primer paso para su aplicación, involucra a la alta dirección y su papel en el proceso de transformación es clave para brindar coherencia y credibilidad a las nuevas formas de gestión.

Sin embargo, uno de los entrevistados, afirma que aún es difícil que las organizaciones tomen un verdadero compromiso con un cambio en la gestión.

Respecto a los cambios a nivel operativo, señala la entrevistada $E$, las modificaciones propuestas como reuniones predictivas entre un analista de Recursos Humanos, un supervisor y un vendedor, produjo un aumento en los niveles de venta y sirven para la motivación y compromiso del empleado con la tarea y con la organización.

- Los beneficios de las nuevas formas de gestión.

Los entrevistados A y B, expresan que las nuevas formas de gestión traen aparejados mejoras en los niveles de ausentismo, rotación, aumento de la productividad y una mejor adaptación del entorno. La entrevistada $E$, afirma que el resultado del cambio va a depender de la naturaleza del mismo (si son de procesos, remunerativos etc) y estos pueden traer aparejados reducción de costos, mayor compromiso y una mejora en el clima organizacional.

- Las redes sociales usadas para el reclutamiento de personal.

Todos los entrevistados manifestaron haber utilizado las redes sociales para las tareas concernientes al reclutamiento del personal; no así para la selección. 
La utilización de las mismas se realiza una vez que ya han revisado sus bases de datos y no se ha hallado el perfil buscado para el puesto: hay organizaciones que utilizan su propio software de Reclutamiento y Selección: por ejemplo, en el caso de la entrevistada D, lo utiliza para conocer el curriculum vitae de los postulantes y también le permite anotar las acciones realizadas para con ellos y los resultados de entrevistas, test, entre otros aspectos.

También hay reclutadores que hacen una diferencia entre qué red social es conveniente utilizar: tal como manifiesta la entrevistada $E$, para puestos menos calificados, como lavaderos, albañiles y otros oficios similares, se utiliza Facebook, una publicación en el diario, o, si la búsqueda es en un área muy delimitada, hasta puede publicarse la búsqueda mediante publicidad de radio; mientras que para puestos más calificados, se realizan publicaciones en Linkedln informando la búsqueda y luego, se analizan los perfiles que se postulan.

Con relación a este aspecto, un entrevistado sostuvo que "Si bien la tecnología nos atraviesa y si bien nos facilita algunas cosas, el trabajo persona - persona es irremplazable; porque en general, siempre trabajamos por y para otros; inclusive hoy, con las nuevas modalidades de trabajo como en los coworking, trabajamos en red, mas o menos tangibles. Cuando uno trabaja en procesos de selección y reclutamiento, es cierto que hoy los jóvenes, ya no ven los diarios, hoy se utilizan las redes, bolsas de trabajo, linkedin, donde las personas vuelcan sus experiencias, a traves de las redes, uno puede hacer un filtro."

Sólo la entrevistada E manifestó utilizar headhunter para reclutar personal, lo que permite ver que ésta técnica es poco utilizada por los reclutadores en Mendoza.

- $\quad$ Fuerte papel de la entrevista tradicional

Cuatro de los cinco entrevistados siguen utilizando éste método ya que sirve como un primer acercamiento y la evaluación de las conductas psicológicas del candidato, puesto que permite la evaluación de la personalidad del candidato, lo cual es importante para saber si esa persona va a poder adaptarse al puesto/organización o no, sirviendo también para verificar datos u obtener más información que en el curriculum vitae no aparece, etc.

El uso de entrevistas mediante teleconferencias o videollamadas se hace en el caso en el que la distancia física entre entrevistador y candidato lo merezca, pero no suele ser una constante en el trabajo diario de los reclutadores entrevistados. 
Es relevante incorporar el comentario personal que ha tenido un entrevistado en cuanto a las entrevistas vía skype o teleconferencias: "Con los procesos de entrevistas por skype o teleconferencias, sí se puede hacer una parte del proceso, nada reemplaza a la entrevista cara a cara y poder tomar algunas técnicas. Desde mi mirada de psicóloga, los profesionales con los procesos de psicotécnicos y de evaluación psicológica, hacen mucho hincapié en aquellas características para poder describir como es esa persona trabajando, si es el perfil de la persona, ya sea de sus competencias adquiridas o sus potenciales, si son las adecuadas para ese puesto, en ese momento, en esa organización, con esa cultura organizacional con el entorno con la que le va a tocar. Porque no es solo elegir a esta persona para este puesto, sino tener en cuenta el cúmulo de cosas que están pasando en la organización en ese momento (qué jefe le va a tocar, si el jefe quiere o tolera las competencias que tiene la persona, de qué manera quiere que ese sujeto sea proactivo, adaptable o si, por ejemplo el perfil dice que la persona necesita ser proactiva, pero ese jefe no quiere que sea proactivo, es temeroso porque piensa que puede sacarle el trabajo, va a querer a alguien mas docil, que pueda recibir órdenes, o que sea mas expresivo) uno tiene que tener un buen feed back con la organización para poder determinar que es lo más adecuado para ella. Esto se logra con una buen analisis de la personalidad."

Con relación a este tema, y en especial en cuanto a la merituación en cuanto a efectividad de las nuevas técnicas, vale la pena rescatar la siguiente opinión de una entrevistada:

"Todo lo que es via internet hoy, hay una serie de cuestionarios, que en realidad sufren el sesgo de deseabilidad (contestan lo que creen que el otro quiere escuchar y no lo que realmente responderían), en cambio, cuando los sujetos realizan técnicas proyectivas, como el test Persona - Casa- Árbol, el sujeto por mas que conozca cuáles son las respuestas deseables el trazo sigue siendo innegable, el grosor del mismo, la profundidad, etc. y uno se termina jugando en la técnica, porque el ser humano dice mas de lo que sabe, es decir, queda en evidencia sus pensamientos. Y es mas fácil de ver si el sujeto está mintiendo, ya que se pueden tomar varias de estas técnicas y pueden correlacionarse las mismas, y por más que le hayan dicho cuál es el dibujo perfecto; uno es lo que es, entonces, uno no puede mentir por como es, las competencias nos hablan de ciertas características (como una persona se enfrentó a una u a otra situación), pero no su personalidad de base, por ejemplo, que hacen que un sujeto sea predispuesto a los accidentes, que es algo que nunca confesaría en una entrevista de trabajo o si tiene conductas poco honestas, o si es organizado o no, mas allá de 
lo que pueda decir o mostrar; Una buena lectura de las técnicas proyectivas hace que la posibilidad de informar sobre ese sujeto, sobre su forma de relacionarse, de desempeñarse, sea mucho mas rica que un cuestionario; los cuestionarios están estandarizados entonces hablan sobre $x$ cantidad de modelos, entonces el sujeto queda encasillado en ciertos modelos determinados y nadie es igual a nadie; entonces, obviamente que requiere de muchísimo mas ejercicio y mucho mas tiempo, ver como se han combinado unos elementos de un sujeto con otro, aunque el puntaje o el percentil nos haya determinado que en tal estilo, por ejemplo el MBTI, estos dos dieron con la misma clasificación, pero puede que los sujetos tengan desempeños distintos y eso lo da las técnicas proyectivas."

- $\quad$ La evaluación de habilidades interpersonales

La utilización de test psicológicos es aún una herramienta que se utiliza frecuentemente para poder descartar u obtener otra información de los candidatos. Las psicólogas entrevistadas aún ven con buenos ojos el uso del Test Casa Árbol, aún cuando ya las respuestas óptimas pueden conocerse a través de internet; ellas manifiestan que, más allá de que el concepto del dibujo esté bien, también evalúan trazos y otros detalles que ponen en manifiesto la personalidad del candidato.

Si bien existe la tendencia de la evaluación mediante uso de aplicaciones y otros medios interactivos, estos aún se encuentran en desarrollo en nuestra provincia y la mayoría de los proyectos siempre cuentan con el apoyo de psicólogos y/o profesionales en la selección de personal que colaboran con el diseño de las mismas.

Una mirada crítica sobre este tema fue planteada por un entrevistado, dado que expresó que "Si es cierto, que hay ejercicios de simulación en las técnicas para ver actitudes, habilidades concretas que permiten que el sujeto pueda medir, programar, que le diseñan esas pruebas a modo de video juegos, que podés medir ciertas aptitudes, pero no características de la personalidad. Serviría solo para una parte de su desempeño, por ejemplo, los simuladores de vuelo a los que son sometidos los aspirantes a pilotos de avión; puedo ser muy hábil para manejarlo, pero no puedo tener la personalidad para manejar una situación de emergencia con la histeria de los pasajeros. Son distintas situaciones"

También es importante destacar el uso de las pruebas de trabajo o Assestment Center, cada vez más para puestos jerárquicos. Afirmaron los cuatro de los referentes consultados que de este modo pueden evaluarse las habilidades blandas que tienen relevancia en este tipo de puestos como estilos 
de liderazgos, comunicación, toma de decisiones y todos ellos tuvieron experiencia en su utilización y la misma fue exitosa.

- La importancia de un buen diseño de puestos

Las personas entrevistadas señalan que el primer paso para un buen reclutamiento y selección, es tener un diseño de puestos adecuado. Para ello, además de la buena descripción de la tarea, es necesario tener en mente en qué equipo de trabajo se incluirán, quién es el líder del mismo para poder describir qué características tiene que tener la persona a cubrir la vacante.

Para quienes trabajan en consultoría, manifestaron que, para lograr dicho objetivo, es necesario tener varias reuniones con los interesados a cubrir el puesto de modo tal de poder realizar un buen análisis de la cultura organizacional, las características y tipo de líder que tendrá esa persona además de las tareas y responsabilidades que tendrá a su cargo.

- La utilización de los softwares de Recursos Humanos

Dos de los profesionales consultados usan el software de Recursos Humanos: una consultada lo utiliza en el reclutamiento y selección mientras que otra profesional utiliza más los módulos administrativos: mantenimiento de legajos e impresión de bonos de sueldos. Estos cambios agilizan la búsqueda de información.

En este capítulo, se expuso el trabajo de campo realizado para ésta investigación. A través de la misma, se intentó dar aproximación acerca de las nuevas formas de gestionar personal y las herramientas 2.0 utilizadas para el reclutamiento y selección, desde el punto de vista de profesionales del área de RR.HH y consultores. 


\section{CONCLUSIONES}

En el presente trabajo se presentaron las formas tradicionales e históricas de gestionar el recurso humano y también se observaron las nuevas tendencias que han surgido en los últimos años. Según las entrevistas realizadas, se puede decir que estas nuevas formas aún están en una etapa experimental y no se puede analizar su eficacia en la aplicación; sin embargo, son el punta pie inicial para mejorar la cultura organizacional y el bienestar de las personas y de la organización. Aun en Mendoza, son pocas las organizaciones que han innovado en este sentido: esto es debido a que los cambios tienen que tener el real compromiso de toda la organización, empleados y directivos deben estar involucrados en estos procesos.

Por su parte, también se realizó un recopilatorio de las herramientas tradicionales para este tipo de tareas y qué permiten evaluar; así como también se realizó una investigación de cuáles son las herramientas actuales que se utilizan para estas tareas.

Respecto a las entrevistas realizadas se puede concluir que en las tareas de reclutamiento de personal se utilizan las herramientas de redes sociales disponibles, siendo por preferencia, Linkedln la más adecuada para esta tarea, pero pueden publicarse las ofertas de trabajo en otras redes para llegar a más público, pero luego, el análisis pasa a manos del reclutador.

En cuanto a la selección, y de acuerdo a lo consultado a expertos, las tareas utilizadas al día de hoy siguen siendo los psicotécnicos y la entrevista personal por excelencia; esto es así, en primer lugar, debido a la confianza del reclutador a su propia experiencia y en segundo lugar a que aún no se encuentran disponibles en Argentina las herramientas necesarias para poder realizar un correcto análisis de personalidad de manera remota. Para el caso de las búsquedas de profesionales de niveles jerárquicos, la utilización del assesment center es la más utilizada.

Las entrevistas realizadas dan la evidencia de que aún quedan muchas innovaciones para incorporar al área de personal, tanto en la forma de gestionar como en el reclutamiento y selección. Es importante destacar que, aun teniendo las herramientas disponibles, la falta de fiabilidad de las mismas contribuye una barrera para que no se las utilice en estos momentos de forma plena como en el caso de la selección de personal y de habilidades blandas. Probablemente, a medida que el tiempo transcurra y la tecnología avance, podrán aplicarse. Sin embargo, dado que la gestión de personas es más sensible e implica, más que nada, un cambio cultural y una convicción desde la 
cúpula de las empresas de que el conocimiento, el bienestar y los valores de los miembros de la organización tienen una relevancia importante y hasta podrían constituir una ventaja competitiva.

Se comprueba así la hipótesis del trabajo, en cuanto a que la aplicación de las herramientas 2.0 permite una mayor eficiencia en la tarea, con la salvedad de que aun las organizaciones y las personas responsables en estas tareas están en plena adaptación y utilizado la mayor parte de las herramientas presentadas para tareas de reclutamiento, no así en selección. Esto se debe a que aún no está, conforme a las entrevistas realizadas, disponible en Mendoza la tecnología adecuada para realizar dichos procesos y aún se mantiene una alta confianza a la experiencia e intuición del profesional que realiza la tarea. 


\section{Bibliografía}

Adecco. (2018). Informe Infoempleo. Madrid: The Addeco Group.

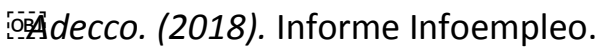

Alles, M. (2013). Dirección Estratégica de Recursos Humanos. Ediciones Garnica S.A.

Andrés Reina, M. P. (2004). Nuevos Procedimientos en el Proceso Empresarial de Provisión de Candidatos: el Relcutamiento on line. Cuadernos de Ciencias Economicas y Empresariales, 47, 89-110.

Angulo Rincon, R. (2017). Gestion del conocimiento y aprendizaje organizacional: una visión integral. Informes Psicológicos, 17(1), 53-70.

Benjamin, Spar; Ilya, Pletenuy; Kate, Reilly; Ignatova, Maria. (2018). Tendencias Internacionales en selección de personal 2018. Linkedin Talent Solution.

Cabrera Izquierdo, A., \& Rincón Hercules, M. (31 de 05 de 2001). Revistas de Informacion Comercial Española. (791), 77-91.

Chiavenato, I. (2001). Admnistración de Recursos Humanos. Mexico: Mc Graw Hill.

Cuesta, E. M., Ibáñez, M. E., Tagliabue, R., \& Zangaro, M. (Agosto/diciembre de 2009). La nueva generación y el trabajo. Barbarói, 13, 126-138.

Dessler, G. (2009). Administración de Recursos Humanos. México: Pearson Educación.

Dolan, S. L., \& Garcia, S. (2000). Reserch Gate. Recuperado el 17 de 07 de 2019, de http://emeraldinsight.com/0262-1711.htm

Esteban, J. A. (2012). Creación de valor en recursos humanos a través del desarrollo de marca como empleador. Desuto.

Galián Jimenez, M. (Enero de 2018). NUEVAS TENDENCIAS EN LOS PROCESOS DE RECLUTAMIENTO Y SELECCIÓN DE PERSONAL. Recuperado el 25 de 04 de 2019, de http://tauja.ujaen.es/bitstream/10953.1/7907/1/TFG\%20GALIAN\%20JIMENEZ\%2c\%20MARIA.pdf

García Castro, P. E., Gatica Barrientos, M. L., Rosa, C. S., Luis Gatica, K., Vargas Hernandez, R. d., Hernandez García, J., y otros. (2016). Procesos de reclutamiento y redes sociales. Revista Iberoamericana para la Investigación y el Desarrollo Educativo, 6(12).

García-Saíz, M. G. (2011). Una revisión constructiva de la gestión por competencias. Anales de Piscología, 473-497. 
Giacomelli Treviño, R. (Septiembre de 2009). Las tecnologías de información y su aplicabilidad en el proceso de reclutamiento y selección. Denea: International Journal of Good Consience, 53-96.

Gonzalez Sabín, R. (2005). Nuevas tecnologías aplicadas a la gestión de RRHH. Las TIC como herramientas de mejora permanente del capital humano (1 ed.). España: Ideas propias.

Hart, C. (2012). Los experimentos de Hawthorne. Revista Cubana de Salud Pública, 38(1), 156-167.

Irma Angélica Aquino Onofre, L. M. (Agosto de 2016). Revista Caribeña de Ciencias Sociales. Recuperado el 24 de 04 de 2019, de http://www.eumed.net/rev/caribe/2016/08/hcm.html

Laca Arocena, F. A., Mejía Ceballos, J. C., \& Gondra Rezola, J. M. (2006). Propuesta de un modelo para evaluar el bienestar laboral como componente de la salud mental. (I. d. Veracruzana, Ed.) Psicología y Salud, 16(1), 87-92.

Macias Gelabert, C., \& Aguilera Martinez, A. (2012). Contribución de la gestión de Recursos Humanos a la Gestión del Conocimiento. Estudios Gerenciales, 28(123), 133-148.

Morrell Blanch, A., \& Brunet Icart, I. (1999). El reclutamiento del personal en la nueva sociedad informacional. Papers. Revista de Sociología, 173-194.

Nieves Lahaba, Y., \& León Santos, M. (2001). La gestión del conocimiento: una nueva perspectiva en la gerencia de las organizaciones. Recuperado el 4 de 12 de 2018, de http://scielo.sld.cu/scielo.php?script=sci_arttext\&pid=S102494352001000200004\&lng=es\&tlng=es.

Pereda Marin, S., Berrocal Berrocal, F., \& Lopez Quero, M. (Octubre de 2002). Dirección y Organización. Recuperado el 4 de Diciembre de 2018, de Revista de Ingeniería de organización: http://www.revistadyo.com/index.php/dyo/article/view/159

Pereda Marin, S., Berrocal, F. B., \& Quero, M. L. (2002). Gestión de Recursos Humanos por competencias y gestión del conocimiento. Dirección y Organización $N^{\circ} 28$, Revista de Ingenieria de Organización, 43-54.

Perez García, S. (2016). Employes brading : una nueva estrategía diferenciadora. México.

Salanova, M., Martinez, I. M., \& Llorens, S. (2014). Una mirada más "positiva" a la salud ocupacional desde la psicología organizacional positiva en tiempos de crisis: aportaciones desde el equipo de investigación WoNT. Papeles del psicologo, 22-30.

Toniut, H., Ricci, S. d., Dondero, M., Molina, D., Nivollet, D., Ordoñez, V., y otros. (2015). La gestión por valores: una mirada crítica sobre la gestión de organizaciones. Revista Argentina de Investigación en Negocios, 57-69.

Vértice, E. (2007). Selección de Personal. Málaga: Vértice. 


\section{ANEXOS}

Anexo A: Cuestionario a profesionales del área de personal

A. Sobre las teorías de la gestión de personal

1. ¿conoce acerca de los nuevos enfoques sobre gestión de personas?

2. ¿considera que esos cambios son visibles en las organizaciones con las que tiene relación?

3. ¿puede ver un real compromiso en los cambios en la gestión de personas?

4. Mencione a modo de ejemplo, organizaciones en las que vio aplicadas las nuevas formas de gestionar personal

5. ¿qué beneficios tienen los cambios de enfoques en la gestión de personas?

6. ¿En qué áreas o sub áreas puede ver un cambio notable?

B. Sobre las técnicas de reclutamiento y selección

1. ¿Qué fuentes de reclutamiento hoy considera importantes y por qué?

2. ¿Qué técnicas de selección considera relevantes y por qué?

3. ¿Qué puede decir de la aplicación de las nuevas técnicas, son efectivas?

4. ¿Ha estado involucrado de alguna forma en procesos de reclutamiento y selección donde han sido utilizada estas técnicas? 


\begin{tabular}{|c|c|c|c|}
\hline Entrevistados & Ocupación & Cargo & Empresa \\
\hline Entrevistado A & $\begin{array}{l}\text { Consultor de RR.HH, Capacitación } \\
\text { y Coach }\end{array}$ & nsocio Director & $\begin{array}{l}\text { Consultoría. } \\
\text { Tiene experiencia en puestos gerenciales de RR.HH en empresas del medio a nivel } \\
\text { nacional y provincial. }\end{array}$ \\
\hline Entrevistado B & $\begin{array}{l}\text { Consultor } \\
\text { de RR.HH, Capacitación y Coach }\end{array}$ & Consultor & $\begin{array}{l}\text { Consultora a nivel internacional. } \\
\text { Tiene experiencia en puestos de RR.HH del medio }\end{array}$ \\
\hline Entrevistado C & $\begin{array}{l}\text { Psicóloga clínica, organizacional y } \\
\text { docente }\end{array}$ & $\begin{array}{l}\text { y Consultora de RR } \\
\mathrm{HH} \text { y Profesora }\end{array}$ & $\begin{array}{l}\text { RFreelance } \\
\text { Docente en la universidad del Aconcagua, Uncuyo e ITU }\end{array}$ \\
\hline Entrevistado D & Psicóloga & Consultora & Fundación sin fin de lucro - Consultoría \\
\hline Entrevistado E & Técnica en Recursos Humanos & $\begin{array}{l}\text { Analista en } \\
\text { Recursos Humanos }\end{array}$ & Empresa automotriz del medio \\
\hline
\end{tabular}


Anexo B: Respuestas sobre las teorías de gestión del personal

\begin{tabular}{|c|c|c|c|c|c|c|}
\hline Entrevistados & sPregunta 1 & Pregunta 2 & Pregunta 3 & regunta 4 & Pregunta 5 & Pregunta 6 \\
\hline Antrevistado & $\mid \begin{array}{l}\text { Si, los conozco y } \\
\text { los he aplicado }\end{array}$ & $\begin{array}{l}\text { Relativamente. Depende } \\
\text { yrincipalmente del tipo } \\
\text { de organización y la } \\
\text { cultura de la misma }\end{array}$ & $\mid \begin{array}{ll}\text { No, aún falta que } \\
\text { todas } \\
\text { organizaciones } \\
\text { tomen un verdadero } \\
\text { lompromiso hacia } \\
\text { construir otro tipo } \\
\text { de realidad }\end{array}$ & $\begin{array}{l}\text { ONG - Fundaciones, } \\
\text { aplicando } \\
\text { principalmente } \\
\text { gestión por valores }\end{array}$ & $\begin{array}{l}\text { La adaptación al entorno y } \\
\text { la generación de nuevas } \\
\text { partir de esos cambios }\end{array}$ & $\begin{array}{l}\text { He presenciado } \\
\text { cambios principalmente } \\
\text { planes de carrera. }\end{array}$ \\
\hline Entrevistado & $\begin{array}{l}\text { Si, las conoce y ha } \\
\text { aplicado }\end{array}$ & Si, completamente & $\begin{array}{l}\text { Si realmente los } \\
\text { directivos toman el } \\
\text { compromiso del } \\
\text { cambio, puede verse } \\
\text { reflejado en varios } \\
\text { indicadores } \\
\text { también en el clima } \\
\text { organizacional }\end{array}$ & Todo tipo de & $\begin{array}{l}\text { Disminución de los niveles } \\
\text { de } \\
\text { en la lasentismo, aumento } \\
\text { disminución } \\
\text { rotación. }\end{array}$ & $\begin{array}{l}\text { En todas las áreas. Este } \\
\text { tipo de gestiones no } \\
\text { abarca solamente a un } \\
\text { tipo determinado de } \\
\text { área, sino que afecta a } \\
\text { la totalidad de la } \\
\text { organización y para eso } \\
\text { están diseñados }\end{array}$ \\
\hline Entrevistado & $\begin{array}{l}\text { Si, Las conoce pero } \\
\text { no las he aplicado }\end{array}$ & $\begin{array}{l}\text { Las organizaciones con } \\
\text { las que tengo relación, } \\
\text { aún manejan la visión del } \\
\text { hombre economicus. }\end{array}$ & $\begin{array}{l}\text { El compromiso en } \\
\text { los cambios } \\
\text { plependerá } \\
\text { principalmente de la }\end{array}$ & $\begin{array}{l}\text { No puede responder a } \\
\text { la pregunta por que no } \\
\text { conoce organización } \\
\text { donde se aplique }\end{array}$ & $\begin{array}{l}\text { No puede responder a la } \\
\text { pregunta por } \\
\text { donoce que no } \\
\text { donde se aplique }\end{array}$ & $\begin{array}{l}\text { No puede responder a } \\
\text { la pregunta por que no } \\
\text { conoce organización } \\
\text { donde se aplique }\end{array}$ \\
\hline
\end{tabular}




\begin{tabular}{|c|c|c|c|c|c|}
\hline & & $\begin{array}{l}\text { Piensa que son una|visión y apertura que } \\
\text { moda mas que unatenga el fundador o } \\
\text { nueva teoría y le falta dueño de la } \\
\text { tiempo de estudio a la organización. } \\
\text { misma. }\end{array}$ & & & \\
\hline Entrevistado & $\begin{array}{l}\text { Si, las conoce, pero } \\
\text { no las ha aplicado. }\end{array}$ & $\begin{array}{l}\text { No, las organizaciones En la empresa donde } \\
\text { con las que tiene relación está actualmente, no } \\
\text { se manejan de una existe } \\
\text { manera muy tradicional|compromiso y no lo } \\
\text { aún, por una decisión ha podido ver en } \\
\text { del dueño. }\end{array}$ & $\begin{array}{l}\text { No puede responder a } \\
\text { la pregunta por que no } \\
\text { conoce organización } \\
\text { donde se aplique }\end{array}$ & $\begin{array}{l}\text { Al ser consultora, no } \\
\text { puede ver esos cambios. } \\
\text { Esta casi siempre con } \\
\text { Pymes o empresas muy } \\
\text { pequeñas }\end{array}$ & 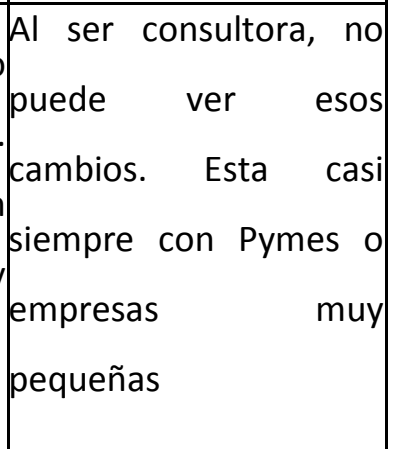 \\
\hline
\end{tabular}




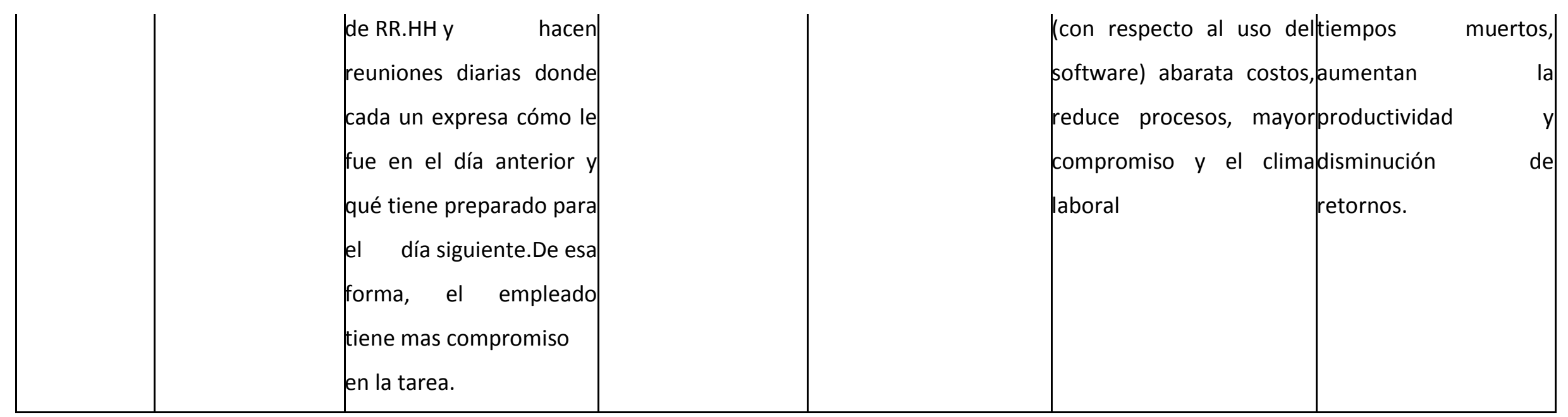




\begin{tabular}{|c|c|c|c|c|}
\hline Entrevistados & Pregunta 1 & Pregunta 2 & Pregunta 3 & Pregunta 4 \\
\hline Entrevistado & $\begin{array}{l}\text { Por redes sociales, vía portales de } \\
\text { empleo. }\end{array}$ & $\begin{array}{l}\text { Assesment Center, por su efectividad, } \\
\text { confiabilidad y mayor objetividad }\end{array}$ & $\begin{array}{l}\text { Si, el reclutamiento digital he tenido } \\
\text { buenas experiencias }\end{array}$ & $\begin{array}{l}\text { Si, he aplicado el } \\
\text { reclutamiento digital y } \\
\text { los assesment center }\end{array}$ \\
\hline Entrevistado & $\begin{array}{l}\text { Si, las conozco. He utilizado la } \\
\text { plataforma de linkedin para buscar } \\
\text { perfiles y videollamadas en el caso } \\
\text { que lo amerite la distancia física. }\end{array}$ & |l personal es & $\begin{array}{l}\text { De las nuevas técnicas, la que } \\
\text { mayormente me causa asombro es } \\
\text { el robot Vera que hace entrevistas. } \\
\text { No lo he utilizado por que no ha } \\
\text { legado al país, pero me parece que } \\
\text { es el futuro en la selección y pasará } \\
\text { a ser una tarea donde el ser } \\
\text { humano tendrá poca injerencia. } \\
\text { y he utilizado, también } \\
\text { el assesment center para perfiles } \\
\text { jerárquicos. }\end{array}$ & é \\
\hline Entrevistado & $\begin{array}{l}\text { Si, las conozco. Actualmente y por } \\
\text { los cambios tecnológicos, se utilizan } \\
\text { Facebook, linkedin, portales y } \\
\text { bolsas de empleo, a partir de ellas }\end{array}$ & $\begin{array}{l}\text { Considera relevantes las técnicas de } \\
\text { selección que son cara a cara puesto } \\
\text { que, como psicóloga, puede aplicar } \\
\text { otras herramientas para detectar mejor }\end{array}$ & $\begin{array}{l}\text { De las nuevas técnicas de } \\
\text { reclutamiento, puedo decir que la } \\
\text { mayoría pueden ser utilizadas para } \\
\text { atraer al candidato. }\end{array}$ & $\begin{array}{l}\text { En alguna ocasión, realicé } \\
\text { alentrevistas } \\
\text { ateleconferencia or } \\
\text { Ilamada. }\end{array}$ \\
\hline
\end{tabular}




\begin{tabular}{|c|c|c|c|}
\hline & $\left|\begin{array}{l}\text { La mo puede realizar un filtro. } \\
\text { La profesional es linkedin. }\end{array}\right| \begin{array}{l}\text { la personalidad del candidato } \\
\text { predecir su comportamiento en el } \\
\text { trabajo. (entrevista personal) } \\
\text { También utiliza test psicotécnicos. }\end{array} \mid$ & $\mid \begin{array}{l}\text { En cuanto a selección, los } \\
\text { cuestionarios on line pueden sufrir } \\
\text { un sesgo de deseabilidad y no los } \\
\text { veo muy efectivos. } \\
\text { Considera la utilización de } \\
\text { videojuegos o simulación, para } \\
\text { algunas profesiones en particular, } \\
\text { por ejemplo pilotos de avión. y } \\
\text { estas técnicas solo servirían para } \\
\text { ver parte del desempeño pero no } \\
\text { para analizar personalidad. }\end{array}$ & \\
\hline Entrevistado & \begin{tabular}{|lrl|lll} 
Utiliza & un software & propio & En & preferencia, realiza & entrevistas \\
llamado Focus Pro Serch que & le & personales y & si & el & perfil lo \\
permite tener la información de & amerita, asessment center. \\
varios candidatos en la red y de & Esta ultima técnica permite un ahorro \\
varias localidades donde AMIA & de tiempo y la evaluación de \\
tiene oficina de empleo. En otras & habilidades blandas que en caso de \\
ocasiones cuando la búsqueda es & una entrevista personal no podrían ser \\
sobre un perfil que no esta en la & evaluadas. También la utilización de \\
base de datos, utilizan portales de psicotécnicos y técnicas proyectivas, \\
empleo o redes sociales
\end{tabular} & $\begin{array}{l}\text { En cuanto al reclutamiento, utiliza } \\
\text { poco frecuente la videollamada en } \\
\text { el caso que lo amerite y el uso es de } \\
\text { primer filtro. } \\
\text { De selección no utiliza. }\end{array}$ & \\
\hline
\end{tabular}




\begin{tabular}{|c|c|c|}
\hline Entrevistado & $\begin{array}{l}\text { Utiliza una base de datos que tiene } \\
\text { de } \\
\text { anteriores, Linkedin para publicar } \\
\text { nuevos avisos y Facebook o avisos } \\
\text { en las radios cuando la búsqueda se }\end{array} \mid \begin{array}{l}\text { er y terarquía, utiliza assesment cent } \\
\text { trata de lavaderos o mecánicos en }\end{array}$ & $\mathrm{t}\left|\begin{array}{l}\text { En cuanto a reclutamiento si. Ha } \\
\text { tenido experiencias inclusive de } \\
\text { head hunter y ha servido más las } \\
\text { publicaciones en Linkedin para } \\
\text { encontrar determinados perfiles } \\
\text { que en los portales de empleo }\end{array}\right| \begin{array}{l}\text { También, se comunica con } \\
\text { acersonas por las redes } \\
\text { trabajo }\end{array}$ \\
\hline
\end{tabular}




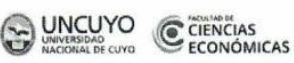

DECLARACIÓN JURADA RESOLUCIÓN 212/99 CD

El autor de este trabajo declara que fue elaborado sin utilizar ningún otro material que no haya dado a conocer en las referencias que nunca fue presentado para su evaluación en carreras universitarias y que no

transgrede $\mathrm{o}$ afecta los derechos de terceros.

Mendoza, 29.... de Agossto de 2019

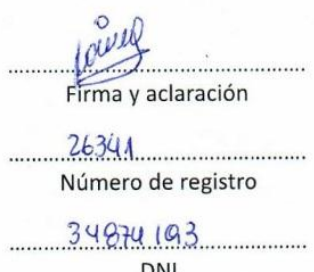

DNI 